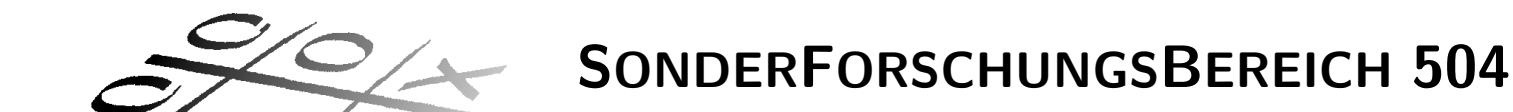

Rationalitätskonzepte,

Entscheidungsverhalten und

ökonomische Modellierung

\begin{tabular}{|}
\hline No. $07-26$ \\
Labor market effects of population aging \\
Axel Börsch-Supan* \\
\hline
\end{tabular}

November 2001

Financial support from the Deutsche Forschungsgemeinschaft, SFB 504, at the University of Mannheim, is gratefully acknowledged.

*Sonderforschungsbereich 504, email: boersch-supan@mea.uni-mannheim.de

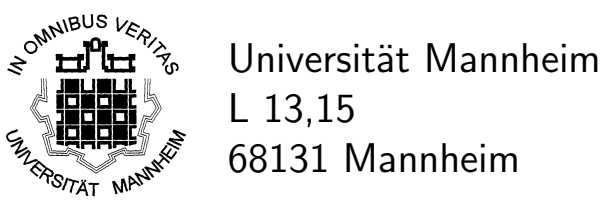




\title{
Labor market effects of population aging
}

\author{
Axel Börsch-Supan \\ Mannheim Research Institute for the Economics of Aging (MEA) \\ at the University of Mannheim, Germany, and \\ National Bureau of Economic Research (NBER), Cambridge, Mass., USA
}

\begin{abstract}
This paper analyzes effects of population aging on the labor market and determines their broad implications for public policy. It takes Germany as an example, but it equally applies to the other large economies in Continental Europe. The paper argues that, alongside the amply discussed, demographically-determined increase in the contribution and tax burden which is responsible for the ever widening gap between gross and disposable earnings, two other important areas of policy deserve greater attention. First, it is unlikely that the decline in the relative size of the economically active population will be offset by higher capital intensity. Labor productivity will need to increase over and above this mechanism in order to compensate for the impact of population aging on domestic production. Hence, we will need more education and training to speed up human capital formation. Second, the shift in the age structure will also change the structure of demand for goods. This, in turn, will have large effects on the pattern of employment across different sectors of the economy and will require a substantial increase in labor mobility in order to accommodate these structural changes.
\end{abstract}

ADDRESS:

Axel Börsch-Supan

MEA, University of Mannheim

D-68131 Mannheim, Germany

Fax: +49-621-181-1861

Email: Axel@Boersch-Supan.de

I would like to thank Anette Reil-Held and Joachim Winter for their helpful comments, Alexander Ludwig, Konrad Menzel and Michael Peters for their research assistance, David Allison for translating this paper from the German original, and the Deutsche Forschungsgemeinschaft, the VW-Stiftung, the Gesamtverband der Deutschen Versicherungswirtschaft and the Land Baden Württemberg for their financial support. 


\title{
Labor market effects of population aging
}

\author{
Axel Börsch-Supan
}

\section{Introduction}

The accelerating pace of demographic change will prove to be one of the key factors shaping the development of society in the coming decades. And yet, although this is by no means a new insight, to date public debate and academic research on aging has for the most part focused on the impact of demographic trends on social policy, and in particular on the problem of financing public retirement income provision. However, demographic change will also induce profound macroeconomic structural changes which will exercise an influence on all the key markets - the labor market, the markets for goods and services, and capital markets. We take Germany as an example, but the paper equally applies to the other large economies in Continental Europe.

- Demographic change will have a massive impact on production if, in Germany in the year 2035, an approximately $15 \%$ smaller labor force is to sustain today's levels of consumption. This can only be achieved by strong productivity growth which in turn is dependent on increased physical capital intensity and strengthened human capital. Wages will rise, while limited international diversification will reduce the return on capital. While the qualitative nature of these tendencies is undisputed, the quantitative extent of these changes is as yet uncertain.

- Demographic change will have a huge impact on the structure of consumption: demand will shift towards more services and products for older members of the community. Shifts in demand of this nature imply structural change in production with the concomitant frictions, e.g. short-term unemployment, particularly if current levels of sector mobility remain low. The quantitative effects are also unclear. On the one hand, some observers appear to hope that demographic change will, as it were, solve the problem of unemployment automatically. On the other hand, high levels of frictional unemployment may widen the qualification gap producing a situation in which the highly qualified are in short supply and the poorly qualified out of work - exacerbating a phenomenon which is already a cause of concern today. 
- Demographic change will also alter international economic relations. Capital will flow from countries with a relatively old population to those with a relatively young population where the rates of return will be higher. Even if the population of the world as a whole were to grow older, the relative differences in age structure would be sufficient to trigger major movements of capital. This insight is especially important for Germany which already has one of the highest proportions of senior citizens of any country in the world. These capital flows will need to be financed via the balance of payments, however. As a result, Germany is likely to be transformed from one of the world's leading export nations into a net importer. Increased imports go hand in hand with shortages of labor. The quantitative magnitude is once again unclear.

It is important that these developments are anticipated, not least in order to cushion or avert altogether the potentially harsh repercussions and transition problems. While the problems themselves are beginning to show up on the radar screens of governments and international organizations, neither the data nor the models needed to arrive at a quantitative assessment of these developments are as yet available.

This paper focuses primarily on the impact of population aging on the labor market and asks to what extent fiscal and social policy may be able to mitigate potential problems. The paper does not deal in any narrow sense with the central issue of reforming the pension, health and long-term care insurance systems - these issues and others are reviewed by Börsch-Supan (2000c). The present paper aims rather to shed light on the structural changes occurring on the labor market - the age structure of workers, their labor productivity and wage structure. A complementary paper (Börsch-Supan, Ludwig and Winter, 2001) examines the implications of population aging on capital markets. This paper may be regarded as dealing with human capital, while the complementary paper deals with real capital.

The paper is divided into two parts. The first part describes the impact of population aging on the labor market and initially outlines the various forecast scenarios of labor supply development. We then draw on a series of models to estimate the changes in the most important structural features of the labor market. The first part lays the groundwork for the second, significantly shorter part which examines the impact and potential proactive scope of fiscal and social policy. As this is an immensely wide-ranging subject, we have restricted ourselves in this paper to drawing conclusions about one or two key issues: where can the state act to mitigate the effects of population aging on the labor market? 


\section{Part I: The impact of population aging on the labor market}

This part presents the relevant forecasts. How will the size of the labor force develop? What will be the age structure of the active working population? How will the shift in the age structure effect labor productivity? What will happen to wage levels? What feedback effects might potential changes in capital intensity have? How will structural changes on product markets influence labor mobility?

All forecasts are based on a common population projection. We will regard these projections as given and will merely explore some parametric scenarios. These population projections will then be used to determine the size of the working population. In this context consideration will be given to the feedback effects which may arise from population aging and potential fiscal and social policy reforms undertaken in response to demographic change. As we know very little about the elasticity of labor supply and demand, we again will examine these feedback effects in different scenario settings. We then go a step further with variables such as capital intensity and wage levels: these are the results of equilibrium mechanisms and therefore require explicit modeling.

In the following we initially describe our population projection, present various forecasts of the development of the working population, and finally draw on a series of models ranging from simple "shift share" approaches to a general equilibrium model of overlapping generations.

\section{Forecast demographic trends}

Demographic projections are based on the medium variant of the Birg and Börsch-Supan (1999) population forecast. The basic assumptions of this projection broadly conform with those of the "Variant 2a" of the "Ninth Coordinated Population Forecast" carried out by the Federal Statistical Office (2000). This study assumes a stagnating birth rate (a fertility rate of 1.35 births per woman), a continuing increase in life expectancy (up to 80.1 and 86.4 years for men and women respectively in the year 2050), and long-term positive net immigration (on average around 120,000 arrivals a year).

We also vary these assumptions in order to scrutinize their influence and adopt, for example, the alternative assumption of a gradual increase in the birth rate to the levels projected by the UN (1.64 births per woman), a 1.5-year higher and lower increase in life expectancy in the year 2050, and net immigration of plus/minus 100,000 persons. Overall we consider four population projections representing the outer bounds of potential demographic development: 
- Population projection B1: strong aging, constant fertility

- Population projection B2: modest aging, constant fertility

- Population projection B3: modest aging, increasing fertility

- Population projection B4: weak aging, increasing fertility

Based on a population of 82.1 million in 1998, all four variants predict a slight decline in population to between 74.7 million (variant B1) and 81.6 million (variant B4) in the year 2030. In our view, scenario B2 probably reflects most accurately population trends showing a decline of $6.6 \%$ to 77.0 million in the year 2030 .

The author of this paper is not unduly concerned about this decline in population. On the other hand, the old-age dependency ratio (i.e. the ratio of the number of people aged over 60 to the number of 20 to 59-year-olds) increases dramatically from 38.6\% in 1998 to between 76.7\% (variant B4) and 88.4\% (variant B1) in the year 2030 and will, in the most advantageous scenario, almost double. In the most probable variant, B2, the old age dependency ratio increases by a factor of 2.13 to $82.3 \%$. This represents the core of the "aging problem” and relates to the structure, not the absolute size, of the German population. ${ }^{1}$

\section{Forecast labor supply}

While the variant population projections only begin to diverge significantly after the year 2040, assumptions regarding labor force participation are critical to forecast labor supply already in the coming decade. We initially adopt a mechanistic approach in which age, gender and immigrant-related labor force participation rates, predetermined as specific scenarios across the chronological axis, are multiplied with projected population figures. The number of primary pensioners (i.e. persons with claims substantiated on the basis of their own gainful employment) is equal to the number of working people leaving the labor force. Later in this paper we discuss the endogenous nature of wages (section 5) and labor supply in relation to fiscal and social policy (sections 9 and 10).

These feedback effects are taken into account implicitly however in the form of scenarios defined on the basis of assumptions regarding

- Converging male and female labor force participation

\footnotetext{
${ }^{1}$ Population aging and population decline are related phenomena in Germany. This need not necessarily be the case, however, as the example of the USA shows. The birth rate in the USA has not declined as dramatically, while life expectancy has increased by at least as much as it has in Germany.
} 
- Converging labor force participation rates in eastern and western Germany

- Converging immigrant and indigenous labor force participation rates

- Increase in retirement age

- Decline of the unemployment rate

We summarize these assumptions in three labor force scenarios:

- Labor force scenario E1: weak increase in labor force participation

- Labor force scenario E2: modest increase in labor force participation

- Labor force scenario E3: substantial increase in labor force participation

Table 1 shows the concrete assumptions for these three labor force scenarios. In scenario E1 we assume that current labor force participation rates will continue to remain fundamentally unchanged in the future. The labor market will only be relieved to the extent that demographic changes will decrease the pressure of unemployment to some extent leveling the long-term unemployment rate out at around $7 \%$. This scenario assumes in particular that reforms initiated so far will not result in an increase in the retirement age, that female labor force participation rates do not increase to match male participation rates and that those of the eastern states do not converge with those in the West. Finally, the differentials in the labor force participation rates of immigrant and the indigenous population are projected into the future at constant rates. We do not believe that this scenario E1 would be a likely development. The assumption is excessively pessimistic and merely serves to illustrate how great the pressure on fiscal and social policy could become. 
Table 1: Labor force scenarios

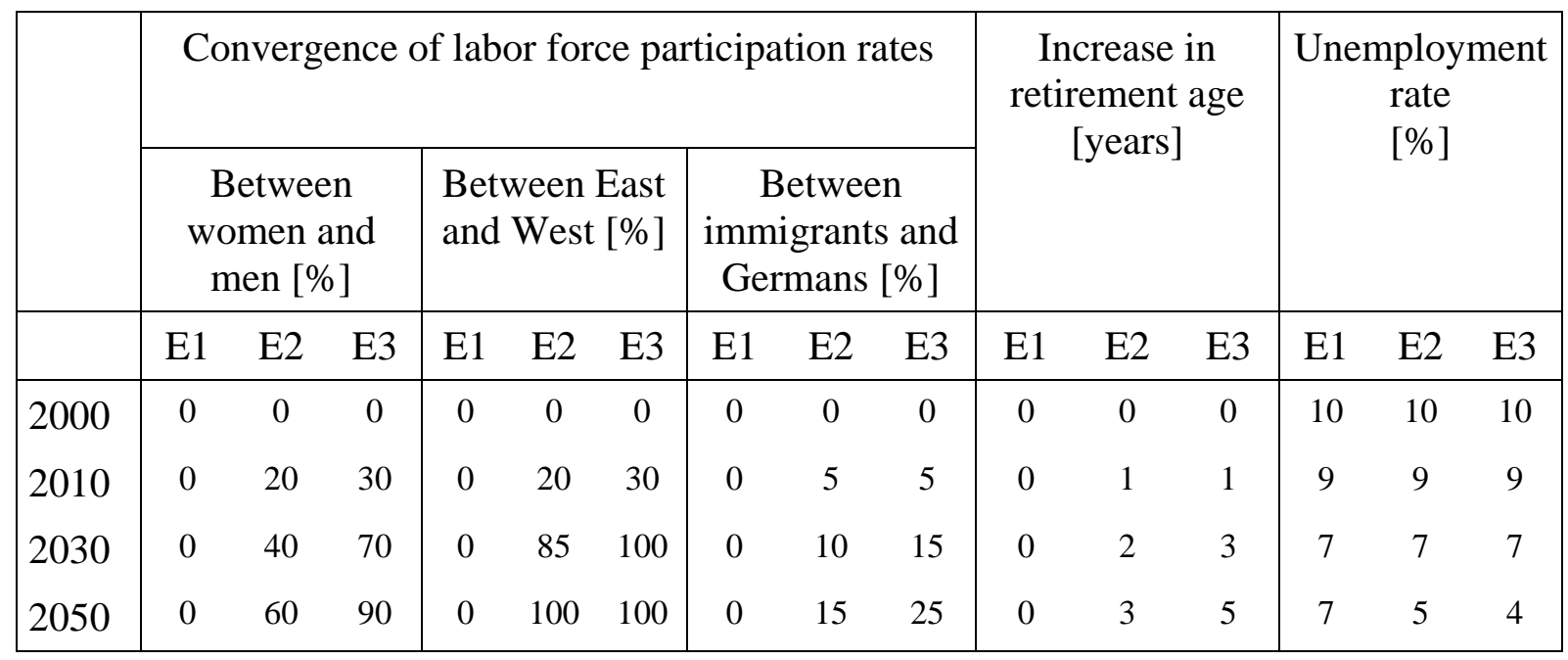

In our view, scenario E2 portrays the most likely development of patterns of gainful employment. In this scenario, the gap is gradually narrowed between the male and female labor force participation rates such that the difference between the two rates will be halved by the year 2040 and should stabilize at around 40\% of the current rate difference in the long term. East German labor force participation rates will have converged with West German rates by the year 2050. The labor force participation rate of the immigrants will also develop positively although it will only converge to a limited extent with the participation rate of the native German working population. The increase in the retirement age shown in this scenario conforms with the results of econometric studies performed by Börsch-Supan (2000b), Siddiqui (1997) and Schmidt (1995) on the consequences of statutory changes to state pension schemes since 1990. These studies foresee an increase in the effective retirement age of 2 years by the year 2030 and of 3 years in the long term. Finally, unemployment will fall sharply by 2030 stabilizing at $5 \%$.

As stressed above, a more elegant approach would, for example, be to draw on a model of the labor market to demonstrate explicitly how patterns of gainful employment might respond to instituted and future pension reform plans. However, in order to do this we would need reliable estimates of labor supply elasticity in relation to net earnings (after deducting social security contributions). No such estimates are available and we shall, for the time being, have to make do with a presentation of different scenarios.

Scenario E3 presents a highly optimistic estimate of developing patterns of gainful employment. In this scenario, the female participation rate will converge almost entirely with 
that of men in the decades ahead. The participation rate for women will be $70 \%$ of the male rate in the year 2030 rising to $90 \%$ in 2050. The labor force participation rate in the new states in eastern Germany will also converge relatively quickly with the rate in the former West German states and by the year 2030 there should be no difference in patterns of gainful employment between both parts of Germany. The participation rate of immigrants will slowly converge with that of the Germans although we also assume below-average levels of activity for this group in the long term. The retirement age rises significantly by 3 years up to the year 2030 and by up to 5 years by 2050. This means that the effective average retirement age will rise from just under 60 at present to almost 65 years. Finally, we assume in this scenario that the shift in the age structure will take considerable pressure off the labor market and will lead to a drop in currently very high rates of unemployment to the long-term natural rate of unemployment which we assume to be $4 \%$. Like the other extreme (scenario E1) also this scenario E3 does not reflect our estimate of the probable development of the labor market. We consider the employment levels predicted by this scenario - a combination of all the most positive circumstances - to be too optimistic.

What follows from these assumptions? The size of the labor force declines dramatically in all three scenarios. This also applies to the very optimistic scenario E3, as shown in figure 1:

\section{Figure 1: Labor force in Germany, 2000-2050 [in millions]}

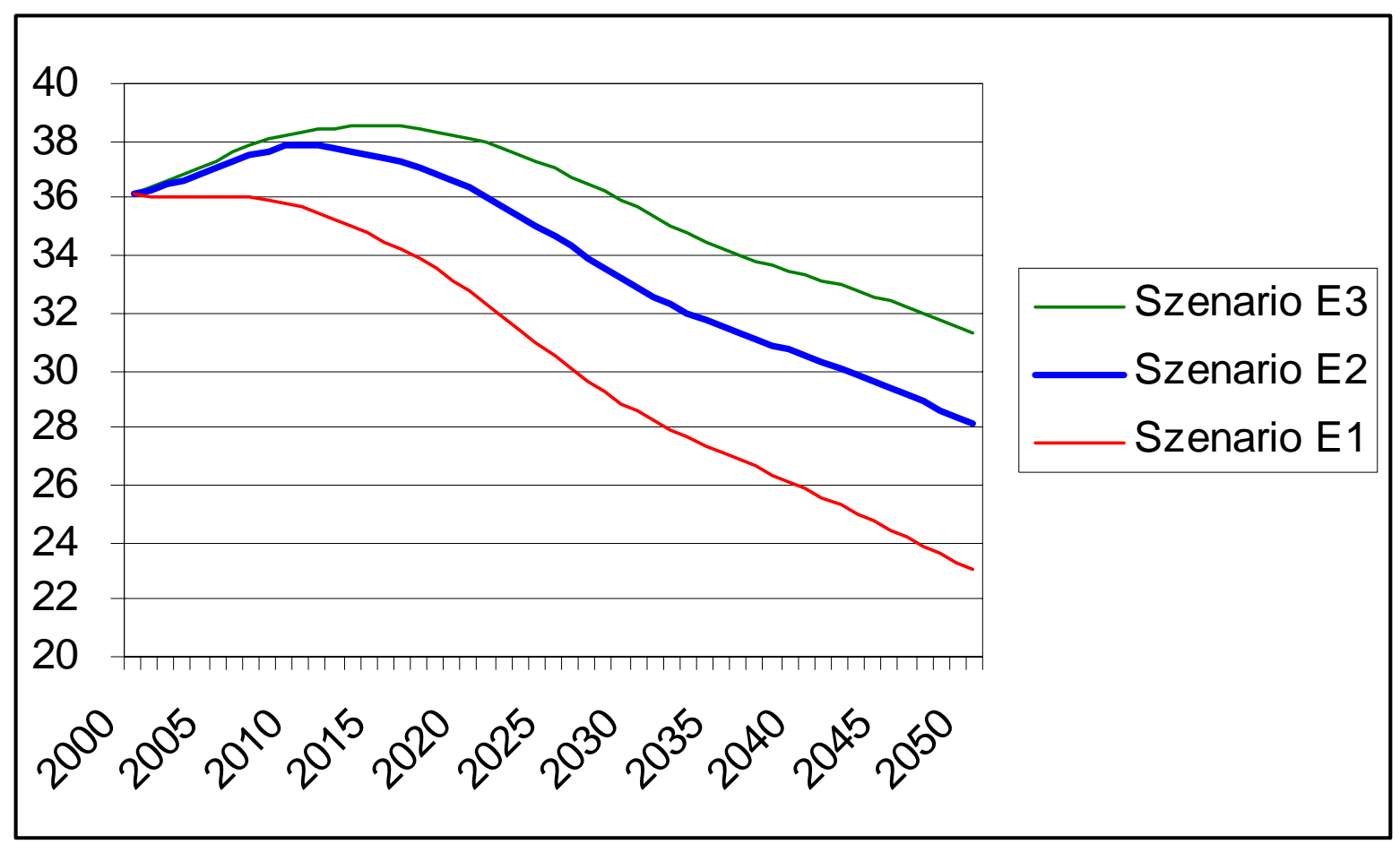

Source: Own calculations based on population projection B2 
Despite the increase in participation rates predicted by the most probable scenario E2, the size of the labor force as measured in the year 2000 is nonetheless set to fall by around 8 million in the long term. In other words the labor market will contract - in absolute terms by more than twice the current number of unemployed.

As the population will also decline, the relative fall in unemployment will not be quite so great however. This is revealed by figure 2 which shows the size of the labor force as a share of the adult population - the so called support ratio. In the average scenario E2, the support ratio drops from 56\% in the year 2000 to $49 \%$ in the year 2035.

Figure 2: Support ratio (labor force as share of total adult population), 2000-2050 [in \%]

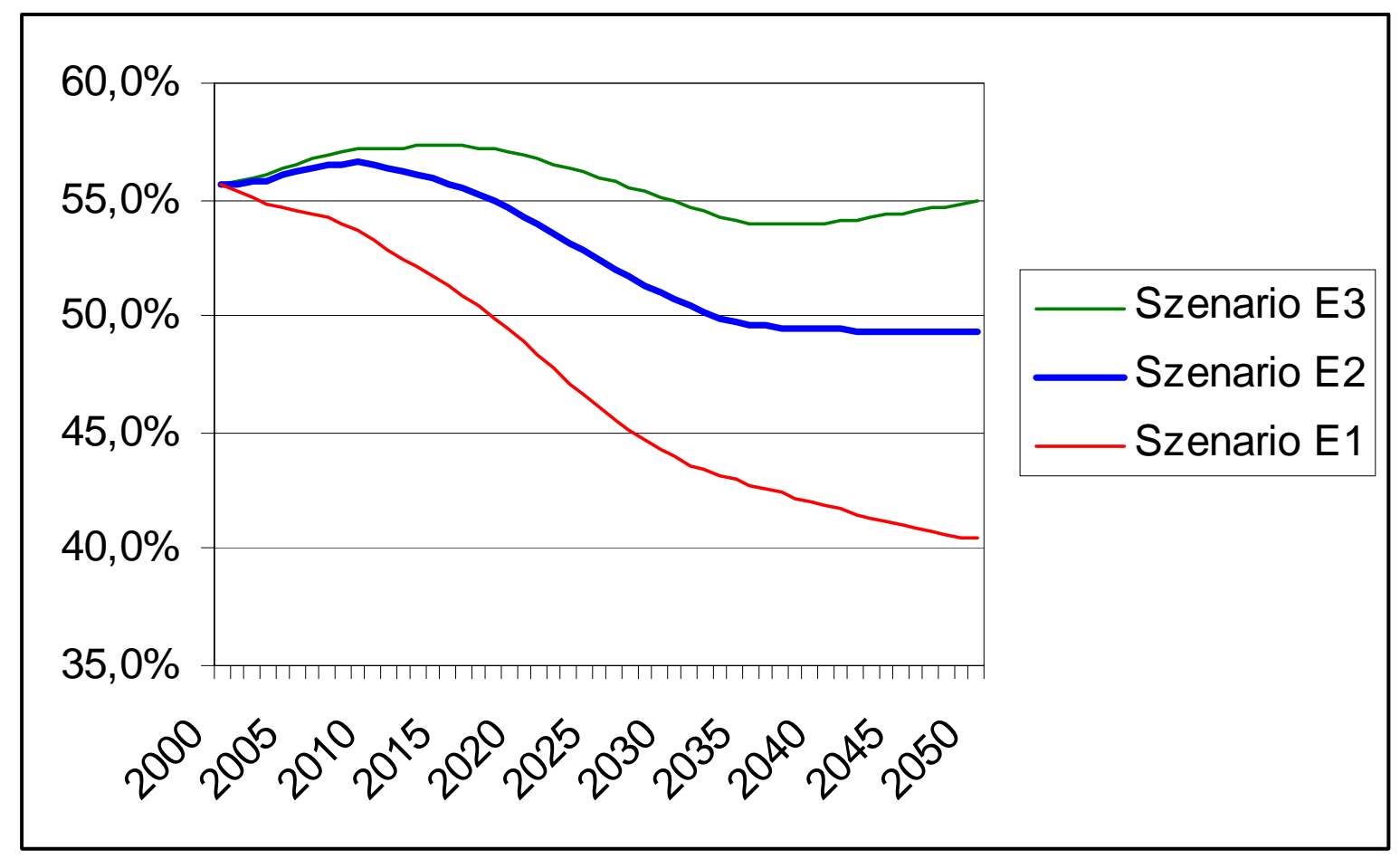

Source: Own calculations based on population projection B2

The support ratio will fall fastest in the 25 year period between 2010 and 2035. This means that in the year 2035 the working population will need to be almost 15\% more productive than in the year 2010 if it is to produce the same per capita quantity of consumer and capital goods. This would require an annual productivity growth rate of around 0.45 percentage points from 2010 to 2035. In other words, around a third of average, long-term real productivity growth of approximately 1.4\% (Buchheim 1998) will be “eaten up” by the relative decrease in the size of the labor force.

This is true of the most probable scenario E2. Figure 2 shows the variability range for this forecast. In the most pessimistic scenario E3, almost half of the long-term improvement in 
productivity is required over a period of 50 years in order to compensate for the drop in the support ratio. On the other hand, in the optimistic scenario E1 the shift in the age structure is compensated for almost entirely by the increase in participation rates.

The first conclusion we can draw from these projections is that we will almost certainly require very strong productivity growth if we are to sustain the rates of growth to which we are accustomed. We shall therefore address the issue of productivity in greater detail in sections 3, 4 and 5 .

However, the contraction in the size of the labor market will be nothing like as dramatic in its effects as the burden of financing pensions which will weigh on the labor force expressed by the so-called old-age dependency ratio (number of pensioners divided by the number of people in gainful employment). This ratio is shown in figures 3 and 4 respectively for each population and work scenario forecast.

Figure 3: Old-age dependency ratio associated with various population forecasts

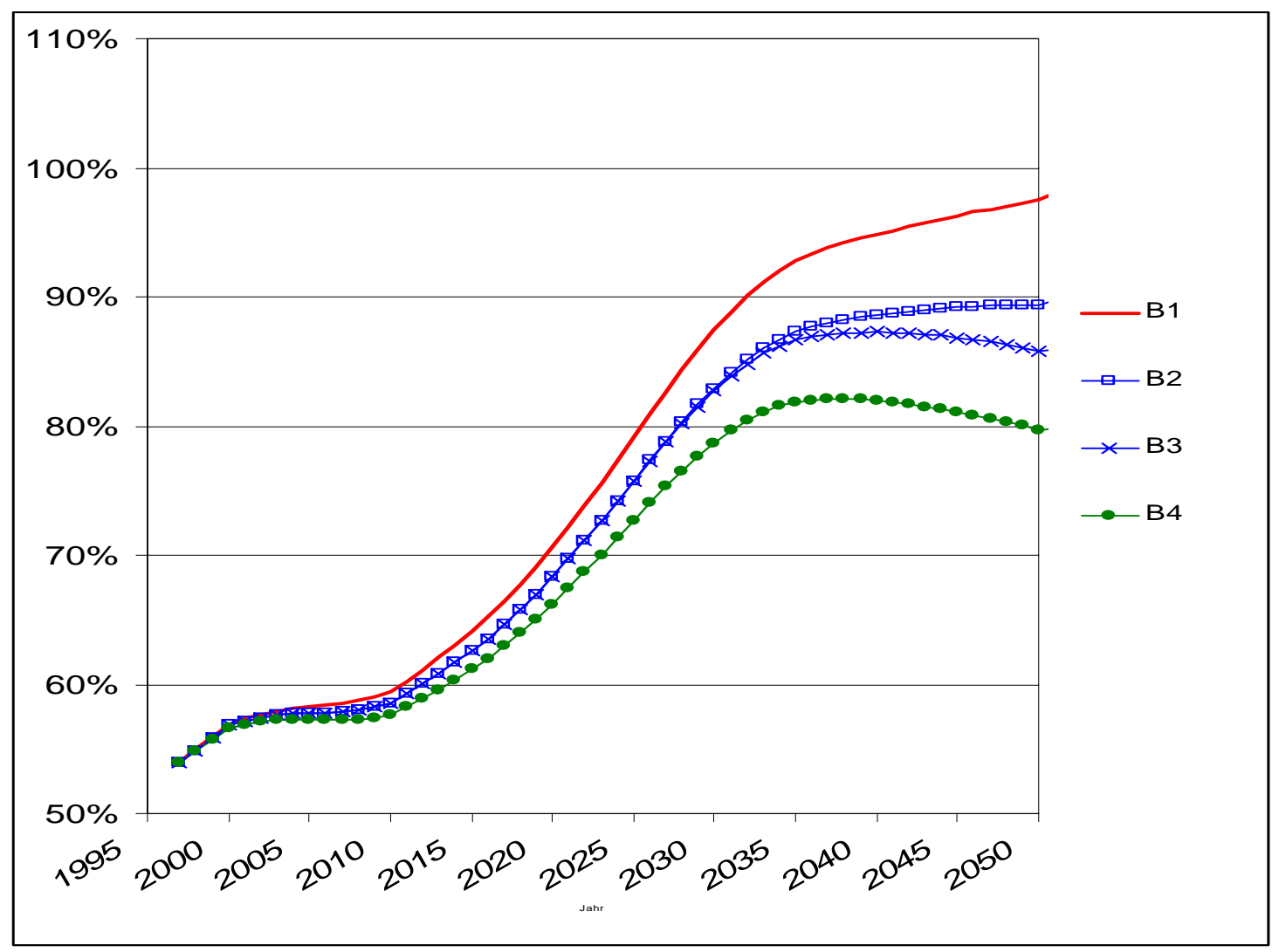

Note: Curves B1-B4 correspond with population forecasts B1-B4 in work scenario E2.

Source: Birg and Börsch-Supan (1999) 
All the forecast variants predict a sharp rise in the old-age dependency ratio. Figure 3 also demonstrates that the aging problem will persist even given a positive turnaround in the birth rate. Differing fertility assumptions only impact after 2035. In the most likely case, the oldage dependency ratio will rise from a figure today of around $55 \%$ to just under $90 \%$ in the year 2035. Depending on the population projection used, the ratio ranges between $83 \%$ and 95\%. "Sidestepping” the aging problem is not therefore an option; the most we can do is to slow the pace of the increase during the "twenties" of the $21^{\text {st }}$ century. In none of the scenarios are the "low" (although in international terms, nonetheless high) old-age dependency ratios of recent decades likely to be re-established in the decades ahead.

This assessment would only be slightly modified by even radical changes in future participation rates as figure 4 reveals. Comparing this with figure 3 , it is apparent that between the two extreme work scenarios there is a far broader range of old-age dependency ratios than there is between the extreme population projections.

Figure 4: Old-age dependency ratio associated with various work scenarios

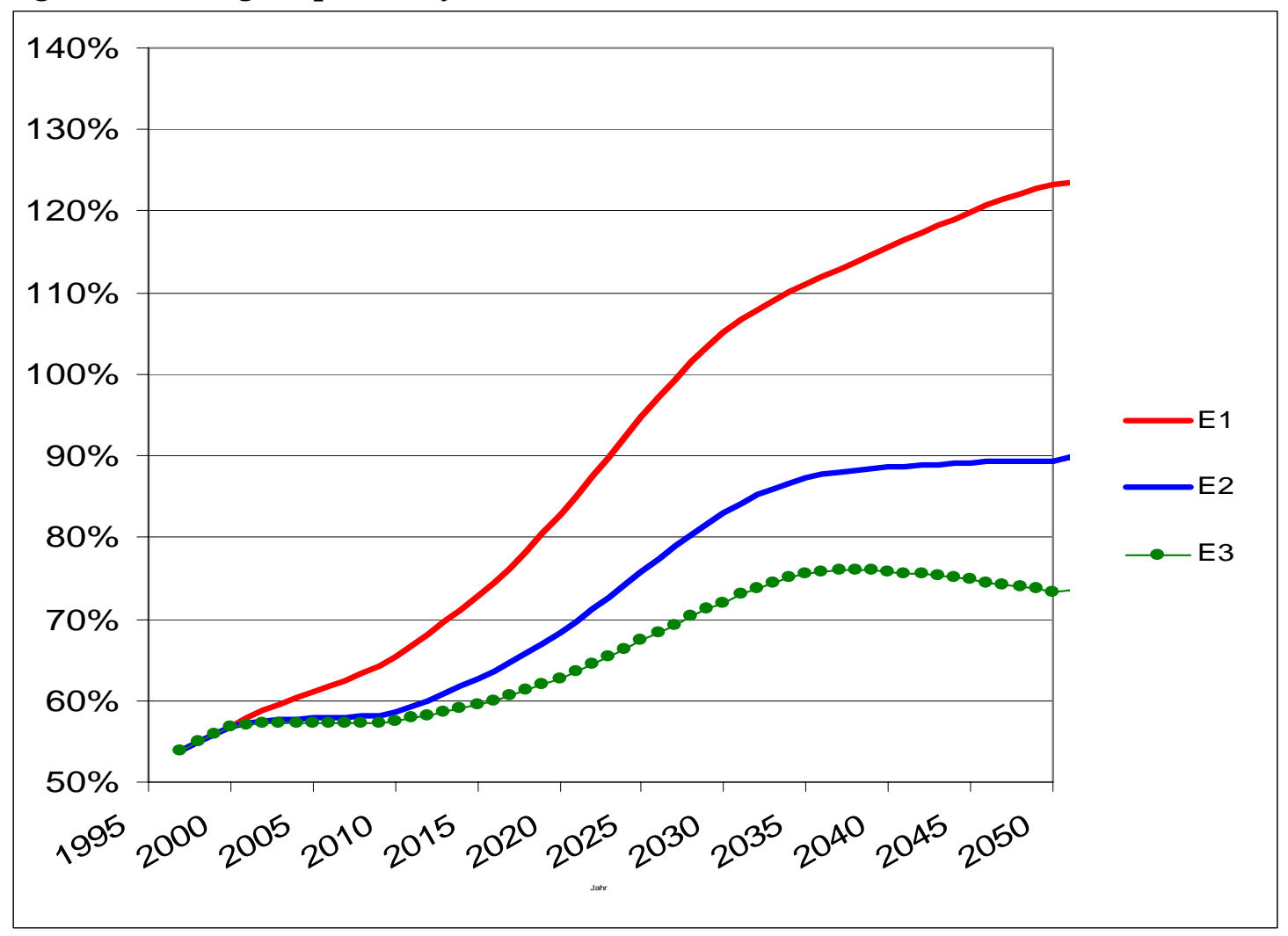

Note: Curves E1-E3 correspond with work scenarios E1-E3 in population projection B2.

Source: Birg and Börsch-Supan (1999) 
In the (unlikely) case of a positive development in gainful employment (E3), the old-age dependency ratio will rise to and remain more or less constant at around 77\%. This scenario hinges on the retirement age being raised by five years, the almost total convergence of the female participation rate and a reduction in the unemployment rate to $4 \%$. It is important to note that the alternative, extremely negative (and equally unlikely) work scenario (E1) does not result in a symmetrically opposite outcome to the positive extreme E3. The old-age dependency ratio deviates by almost twice as much upwards from the reference case showing the most probable work scenario than it does downwards. This means that if the pattern of gainful employment should change negatively, the old-age dependency ratio will reach an extremely high level in the year 2050. If this development takes place (no change in the retirement age, constant level of female work activity, slight reduction in the unemployment rate to $7 \%$ ) the old-age dependency ratio will rise to over $110 \%$ in the year 2030 and will continue to increase in the ensuing period.

In summary: the decline in the working population as a share of the (consuming and investing) population as a whole will “eat up” around one third of long-term productivity growth. In other words: annual productivity gains need to increase by a third if we are to experience the sustained levels of growth to which we are accustomed. More dramatic, however, is the rise in the old-age dependency ratio which, in the most likely scenario, is set to double.

\section{Age structure of the working population}

Not only the size but also the age structure of the working population will change radically in the coming decades. Figure 5 shows the age composition of the labor force between the years 2000 and 2050. The distribution peak very clearly moves from left to right. The modal age today (2000) is 36 years of age; 10 years later this increases to 46 years, and a further 10 years on it has risen to 54 years. The baby boomers then retire - the age distribution curve flattens out and changes very little in the following years. 
Figure 5a: Age structure of the working population, 2000-2050

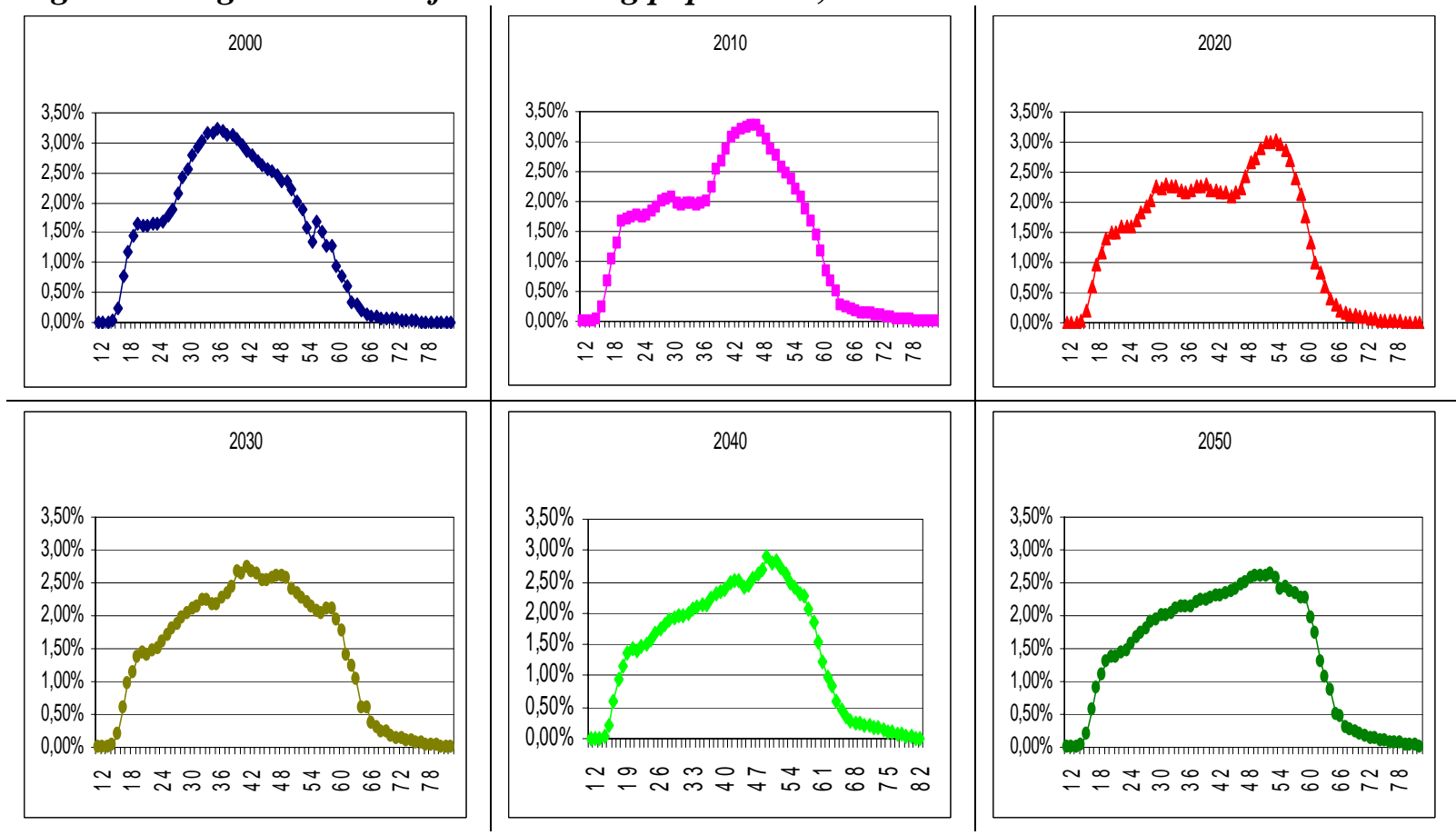

Source: Own calculations based on population projection B2 and work scenario E2.

Figure 5b: Age structure of the working population, 2000-2050

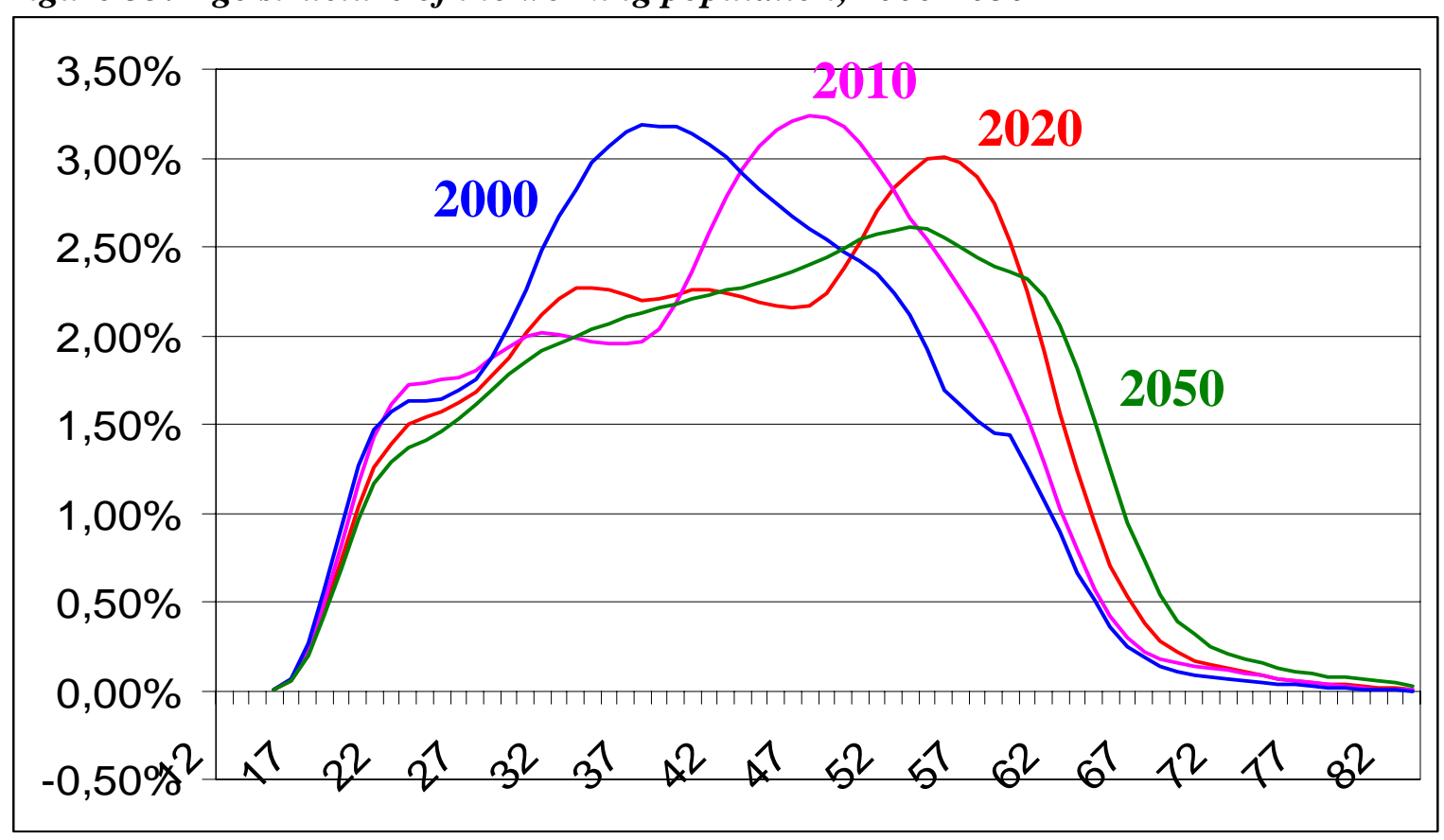

Note: Smoothed variant of figure $5 \mathrm{a}$

The average age of the labor force will increase from 29 to 42.5 years in the next 20 years, will then stagnate for 15 years and subsequently increase by one further year (figure 6a). The dramatic change in the age structure is exemplified in particular by the share of the labor force 
accounted for by workers aged 55 years or older (figure 6b). This clearly demonstrates the temporary "rejuvenation" of the labor force when the baby boom generation retires. The data also reveals - and this is an important message - that the shift in the age structure is not a transitory phenomenon but represents a permanent change.

Figure 6a:

Average age of the labor force

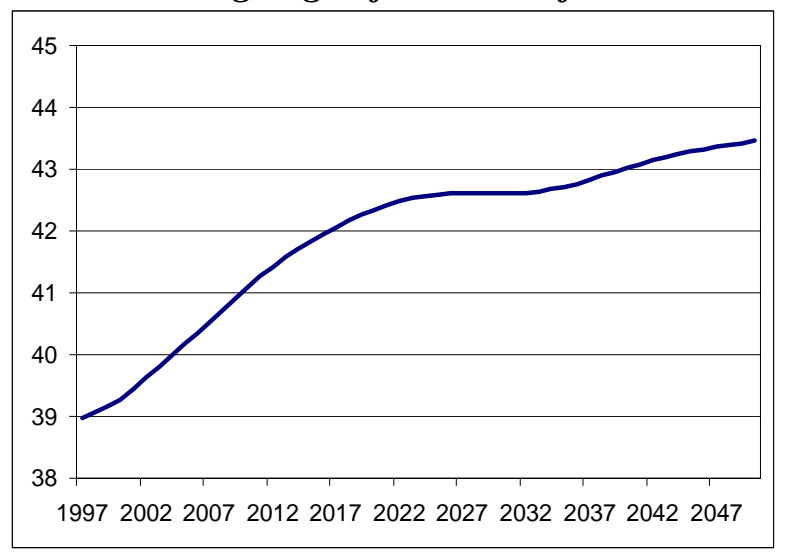

Figure 6b:

Share of the labor force over 55 years

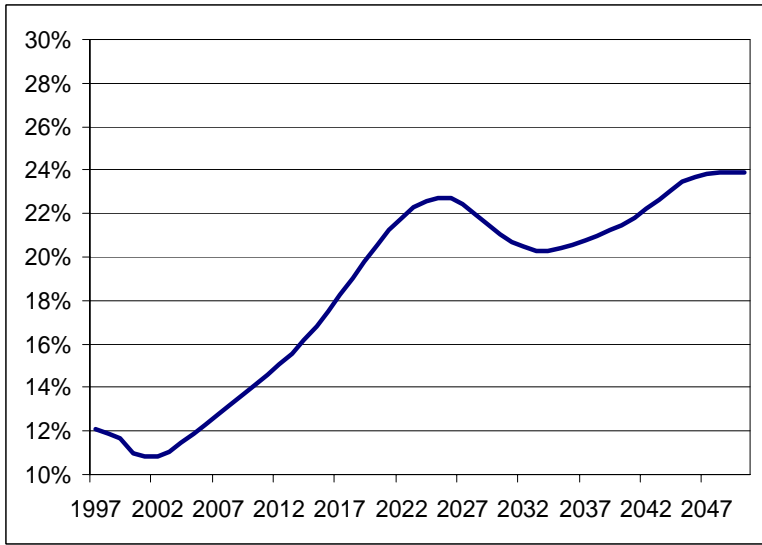

Source: Own calculations based on population projection B2 and work scenario E2.

\section{Age structure and labor productivity}

What effects will this fundamental change in the age structure of the working population have? The most important - and most controversial - aspect is the potential effect on labor productivity. If labor productivity is age dependent, a shift in the age structure will also bring about a change in aggregate productivity, even if age-specific productivity were to remain constant. This section provides a gross estimate of the approximate magnitude of this effect .

This is not a simple task, however, as there is no reliable data available on age-specific labor productivity. Barth et al. (1993) conclude from a survey of human resource executives in 406 organizations that "Older workers were consistently rated as having more positive attitudes being more reliable and possessing better skills than the average worker; they were rated worse than the average worker when it comes to health care costs, flexibility in accepting new assignments, and suitability for training.” Moreover, productivity tends to be a highly individual and sector-specific factor. Labor productivity cannot be "worked out” by means of simple stratification and averaging as workers select themselves in sectors and professions according to their own productivity and this self-selection changes with age - and consequently with the shift in the age structure. Age-specific labor productivity must 
therefore be identified from panel data on individual work input and individually attributable output. Studies based on cross-sectional data confound age, cohort and selection effects.

Modeling these effects would exceed the scope of this paper and, given the scantiness of the available data, would hardly be feasible. See Hutchins (2001) for a discussion of the usefulness of employer survey to address these issues. We therefore take a much cruder approach and simply apply two extreme estimates of age-specific productivity derived from Kotlikoff and Wise (1989) to the German data which should, roughly at least, capture the range of possible effects. The function of these estimates as "strawmen" should become apparent at the end of this section. For this reason, the reader may wish to suspend any detailed criticism of the estimates for the time being.

Kotlikoff and Wise (1989) evaluate confidential data originating from a major US American service enterprise. They provide two estimates. On the one hand, we interpret the age and seniority-specific earnings of sales staff, which are proportionally linked to the value of the sales contracts clinched by such staff, as age and seniority-specific productivity. Figure 7 shows these earnings as a function of age (abscissa) and age on joining the firm (set of curves parameter).

\section{Figure 7: Age and seniority-specific earnings of salesmen}

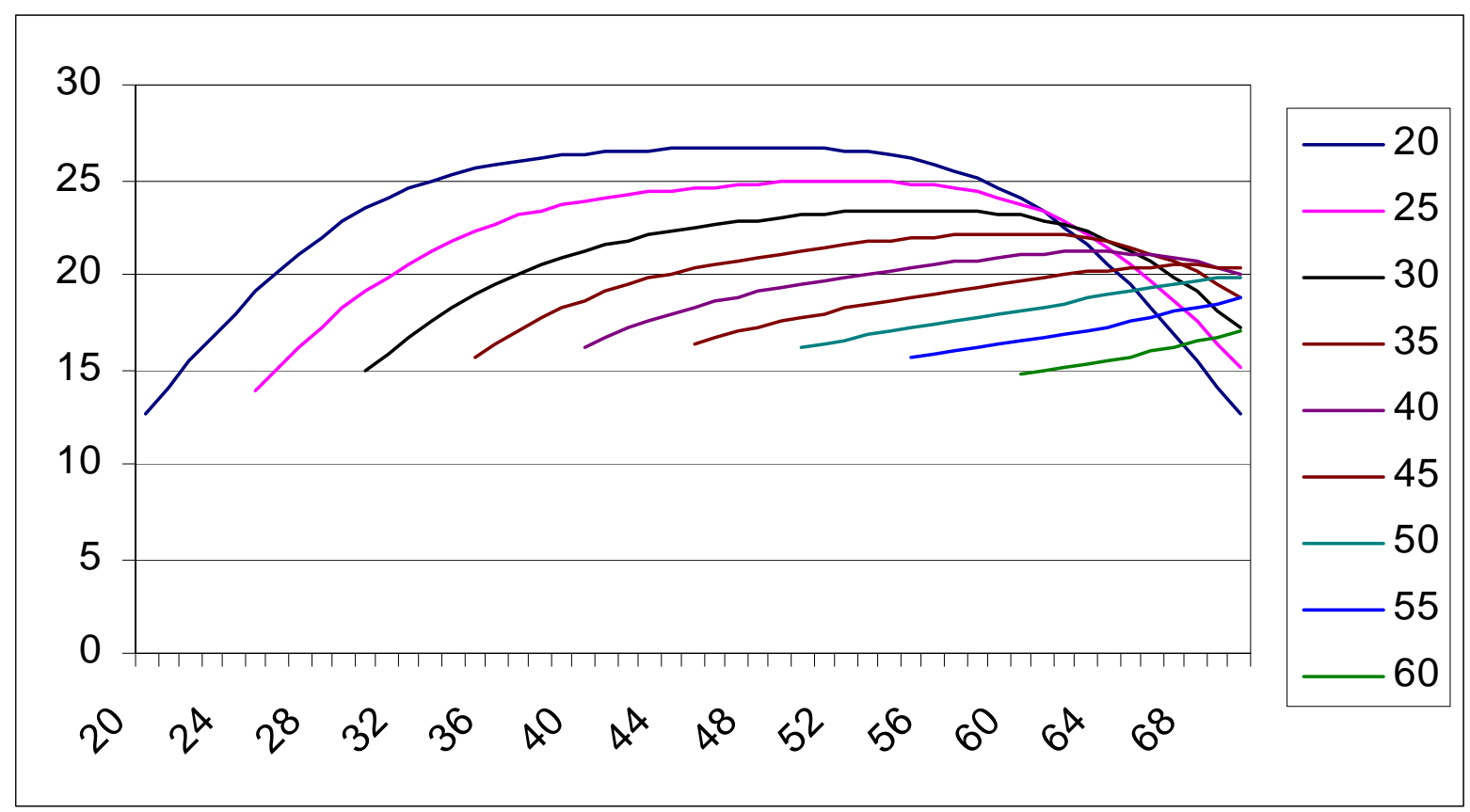

Source: Kotlikoff and Wise (1989) 
As the curves are basically congruent, we draw on the profile of sales employees recruited at the age of 20 for the first estimate of age-specific labor productivity. This curve is relatively flat. The employee's piece rate remuneration more than doubles during the first junior employment period of around 15 years. Piece-rate remuneration - our initial measure of productivity - only begins to fall again between the ages of 55 and 60 years.

Salesmen whose pay is wholly performance related are by no means representative of a modern service economy. We therefore turn to salaried office workers for our second estimate of age-specific labor productivity. The difficulty here, however, is that salaried workers pay generally encompasses a major seniority element which severs the tie between pay and productivity across the life cycle. Figure 8 shows this phenomenon quite clearly: the pay of "novices" is significantly lower than that of the "old hands". The sharp fall which takes place once the age of 60 has been reached is almost certainly a statistical artifact, however, as most of the salaried workers employed by this company take early retirement. The earnings of novices however once again reveal a strong age link. We draw on this age - salary pattern of newly recruited staff as our second estimate for the age-specific labor productivity of salaried workers. This turns out to be considerably “curvier” than the profile shown in figure 7.

\section{Figure 8: Age and seniority-specific earnings of salarymen}

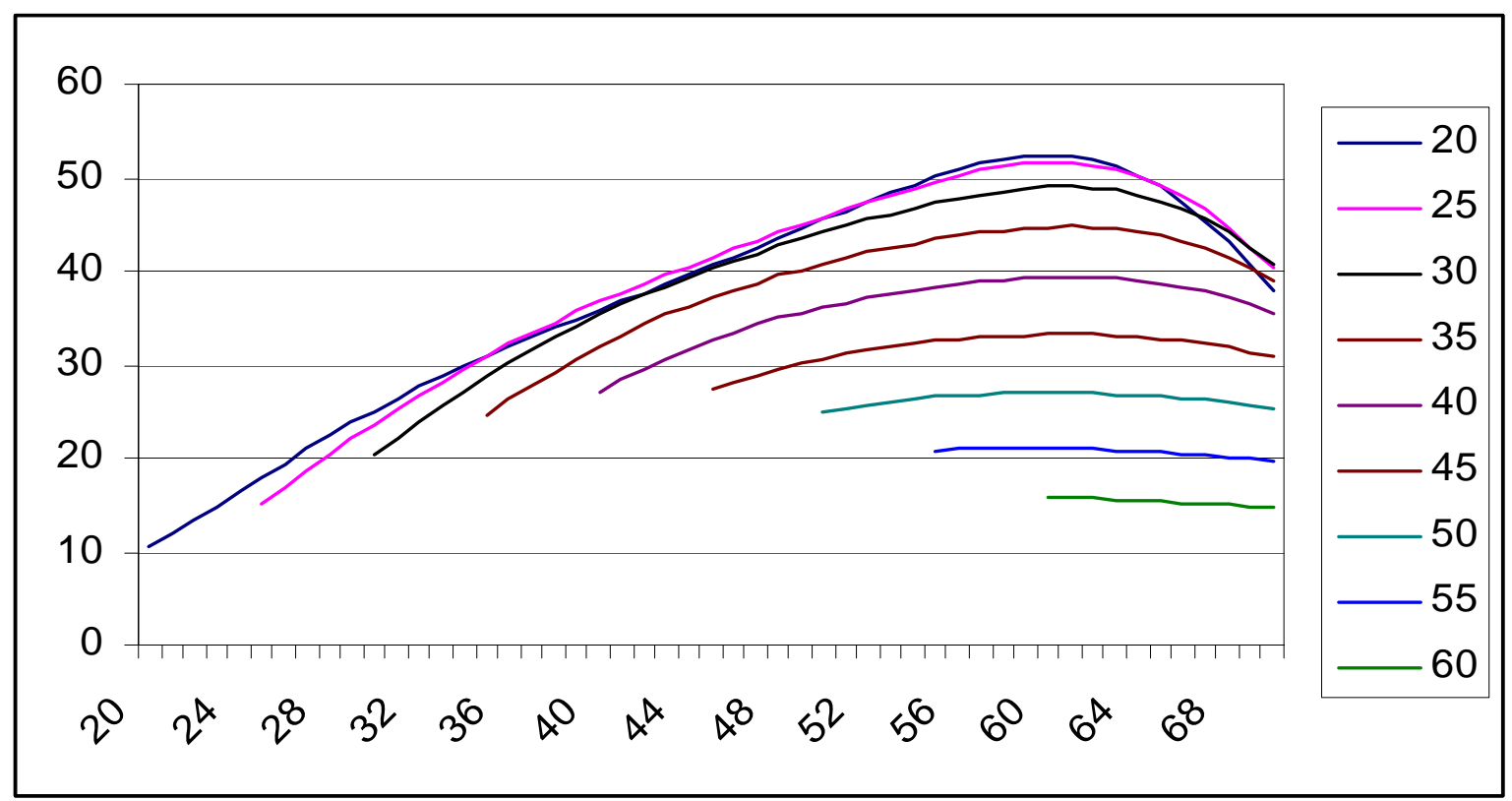

Source: Kotlikoff and Wise (1989)

Table 9 shows the normalized age-productivity estimates. They feature a distinct bell-shaped curve which peaks for salaried workers at the age of 44 years and subsequently falls rapidly 
while sales employees' productivity maximum is reached 4 years later and is much less pronounced. In both cases, our strawman labor productivity is about $20 \%$ of its lifecycle maximum at around 16 years and sinks back down to this level again at 75 years.

Figure 9: Relative labor productivity of salesmen and salarymen

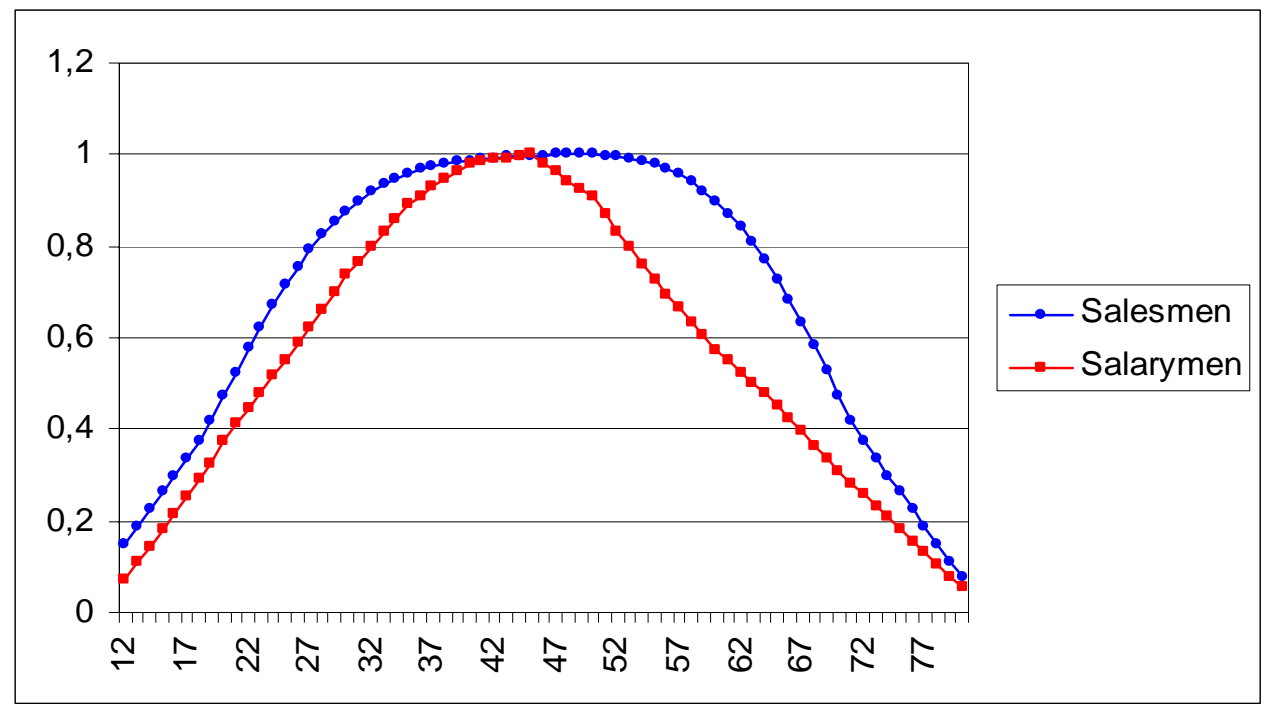

Source: Derived from Kotlikoff and Wise (1989)

The point of this exercise becomes clear in figure 10. We now multiply age-dependent productivity (figure 9) with the gradually changing distribution of the age structure of the working population (figure 5) in order to calculate the time path of the aggregated productivity of the labor force. The results are shown in figure 10.

Figure 10: Relative labor productivity of salesmen and salarymen

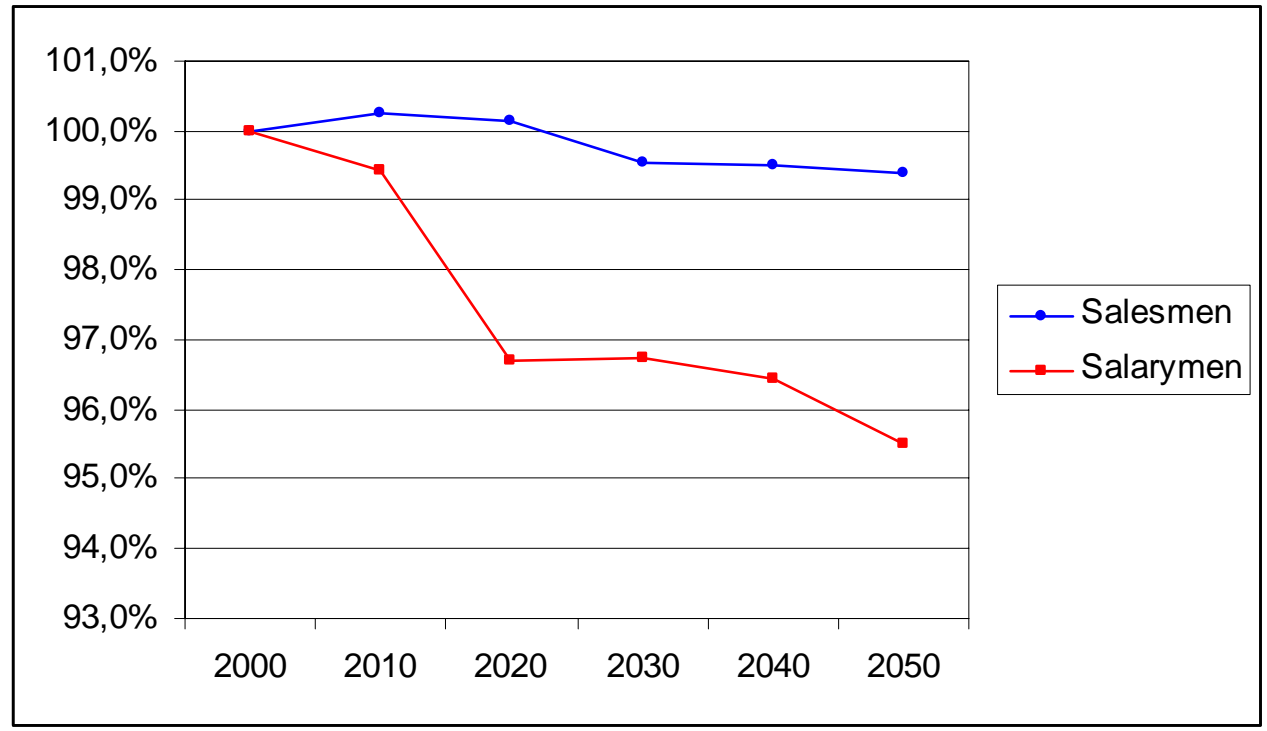

Source: Own calculations 
Despite the marked (and for the reader possibly alarming) age dependency of the labor productivity estimates in figure 9, there is only a minor drop in aggregate labor productivity. If the estimate is based on the productivity of sales staff, the drop is negligible. In the extreme case, in which the estimate is based on recruited salaried workers, the drop amounts to around $3 \%$ in 20 years. This is equal to a reduction in productivity of around $0.15 \%$ per annum. The scale of this change is therefore considerably smaller than the effect of the falling support ratio which we considered in section 2, figure 2. In other words, the potential productivity effects induced by the age structure of the working population are much smaller than the loss of production arising as a result of the fall in the relative size of the economically active population

While more research is certainly needed to measure the relation between age and productivity in all its complex dimensions pointed out by Barth et al. (1993), the main message of this section is therefore that Germany will face are likely severe problems elsewhere, and not through an unproductive old labor force.

\section{Population aging and wage levels}

The mechanistic "shift share" method used in the previous sections ignores any economic equilibrium analysis. The method is used to isolate partial effects and to draw attention to their potential magnitude. This is particularly the case for the results in section 4: Age structure related productivity effects are also likely to be small when regarded in an equilibrium framework.

We go a step further in this and the following section and analyze the equilibrium effects of population aging on the labor market. Section 2 demonstrated clearly that population development in the decades ahead implies that labor will become a relatively scarce resource. Wages will therefore rise and capital will increasingly substitute for labor, i.e. capital intensity will rise and with it labor productivity. This section considers wage levels, Section 6 looks at the development of capital intensity and the productivity effect which these induce.

For the purposes of this analysis we draw on a model of overlapping generations (OLG) developed by Börsch-Supan, Ludwig and Winter (2001) based on the tradition of models established by Diamond (1965) and Auerbach and Kotlikoff (1987). The model used here adds an international dimension and capital mobility. As will become clear, this is an important addition for Germany in particular. We apply the model to two scenarios of capital mobility: firstly to Germany as a closed economy, and secondly to Germany as an open 
economy with perfect capital mobility between it and the other OECD countries. We also vary a political parameter which is important for the formation of wages and capital - the mix of the pension system in terms of pay-as-you-go versus funded.

In the following we sketch out the model's basic equations. For the sake of clarity, the country index has been omitted for the time being. For a more detailed description and critique of the model, refer to Börsch-Supan, Ludwig and Winter (2001).

Our model covers 75 living cohorts; each model period corresponds to a period of one year. Each new generation is already 20 years old when it enters the model and immediately enters gainful employment. Each generation then continues working up to the retirement age of $R$ and remains in retirement until the oldest modeled age of 94 years or up to period 75 . As we are able to vary the size of economically-active or retired generations according to our population scenarios, our stylized model is capable of incorporating demographic developments (such as greater life expectancy) in detail.

We "feed" the German part of the OLG model with the results of the population and labor force forecasts in sections 1 and 2. We use the latest UN projections for the remaining OECD countries (United Nations Population Division, 2000). At each point in time $t$, a number of exogenous variables are thus given: the size of each of the 75 living cohorts, $N_{t}^{a}$, whereby assuming a fixed retirement age of 60 , this corresponds for $a=1, \ldots, 39$ to the size of the labor force $L_{t}^{a}$ aged $a$ and for $a=40, \ldots, 75$ the number of pensioners $Z_{t}^{a}$ aged $a$. We vary the pensionable age on the basis of (exogenous) forecast changes in the labor force. The labor supply remains inelastic in all other respects (i.e. it does not react to endogenous wage and non-wage labor costs). The latter is a fallacious assumption as we shall discuss in sections 9 and 10; however, as stressed a number of times already, modeling social insurance incentive effects would exceed the scope of this OLG model by far.

The core of the model is production technology characterized by a CED production function

$$
Y_{t}=A_{t}\left(\alpha K_{t}^{1-1 / \beta}+(1-\alpha) L_{t}^{1-1 / \beta}\right)^{\frac{1}{1-1 / \beta}}
$$

$A_{t}$ represents (exogenously given) total factor productivity; all other symbols assume their standard meaning. The parameters are shown in Table 2.

On the basis of the constant profit maximization of a representative firm producing on the domestic market we obtain the wage rate (gross earnings)

(2) $\quad w_{t}=(1-\alpha) A_{t}\left(\alpha K_{t}^{1-1 / \beta}+(1-\alpha) L_{t}^{1-1 / \beta}\right)^{1 /(\beta-1)} L_{t}^{-1 / \beta}$. 
The total capital stock in the economy of each country develops according to the recursion

$$
\text { (3) } \quad K_{t+1}=I_{t}+(1-\delta) K_{t}
$$

and defines the capital intensity $K_{t} / L_{t}$.

In the household sector, each generation aged $a$ maximizes, at any point in time $t$, the sum of discounted future utility. We use a within-period utility function with constant relative risk aversion

$$
E\left(U_{t}^{a}\right)=\frac{1}{1-\sigma} \sum_{j=a}^{75} \frac{1}{(1+\rho)^{j-a}}\left(C_{t+j-a}^{j}\right)^{1-\sigma}
$$

to obtain the consumption $C_{t}^{a}$ and wealth $W_{t}^{a}$ of generation $a$ at the point in time $t$. This wealth consists of the shares of domestic and foreign capital stock in the hands of households.

The OLG model is augmented by the pay-as-you-go pension system the determining variables of which are the contribution rate $\tau_{t}$ and the replacement rate $R_{t}$. These parameters are linked with each other by the pension system's budget equation:

$$
\tau_{t} w_{t} L_{t}=R_{t} w_{t}\left(1-\tau_{t}\right) Z_{t}
$$

In effect this constitutes a multi-pillar pension system. The second/third pillars are implicitly formed by household savings generated by the maximization of life-time utility (4). For $\tau_{t}=0$, total retirement income comes from private savings. On the other hand, there is a $\tau^{\max }$ for which the pay-as-you-go system totally crowds out household savings. We use two scenarios. In the first scenario, the replacement rate $R_{t}$ is fixed and the contribution rate $\tau_{t}$ is adjusted to the change in the age structure ("perpetuation of the old pay-as-you-go system"). In the second scenario, the replacement rate $R_{t}$ is reduced as the population grows older such that the contribution rate $\tau_{t}$ remains constant (“freezing model”). As this results in increased savings, this scenario models a gradual transition to a pension system based on a substantially higher pre-funded component.

Four aggregation conditions close the model and ensure market clearing and general equilibrium at all times. Initially, the following applies in all countries:

(6) $\quad W_{t}=\sum_{a=1}^{75} W_{t}^{a} \cdot N_{t}^{a}, \quad C_{t}=\sum_{a=1}^{75} C_{t}^{a} \cdot N_{t}^{a} \quad$ and $\quad L_{t}=\sum_{a=1}^{39} N_{t}^{a}$. 
Finally, the perfect capital mobility produced by a uniform world interest rate $r_{t}$, guarantees that the world capital market will be cleared, i.e. that global wealth equals global capital stock:

(7) $\quad \sum_{i=1}^{L} W_{t, i}=\sum_{i=1}^{L} K_{t, i}$.

The capital account mirrors capital flows and as all goods are tradable, we may disregard real exchange rate effects.

The model's equilibrium paths are determined numerically using a recursive computation. The values used in the calibration of our model are standard in the literature on OLG models (Miles, 1999; Fehr, 1999), refer to Table 2:

\section{Table 2: OLG model parameters}

\begin{tabular}{|l|l|}
\hline$\alpha:$ Factor capital as share of gross national product & 0.4 \\
$\beta$ : Elasticity of production substitution & 0.999 \\
$\delta$ : Depreciation rate & 0.05 \\
$\mathrm{~d} A_{t} / \mathrm{d} t$ : Exogenous rate of technical progress & 0.0139 \\
$\rho:$ Rate of time preference & 0.08 \\
$\sigma:$ Elasticity of intertemporal substitution in consumption & 3.0 \\
\hline
\end{tabular}

We first apply the model to the development of wages. Figure 11 shows the increase in gross earnings in relation to the increase which would have occurred if the population had remained constant. This is positive up to the year 2030, but very minor in both scenarios. It is useful to compare this increase in gross earnings with the rise in disposable earnings if we assume that age-specific public spending values for 1997 are retained and are financed by a corresponding increase in contributions and taxes (perpetuation of the old pay-as-you-go system at 1997 pension levels; similarly, age-specific expenditure by the statutory health insurance and longterm care schemes including all central government financial support). Figure 12 shows that the increase in gross earnings resulting from labor shortages is dominated entirely by the agerelated increase in contributions and taxes.

The main message of this section is therefore that the shift in the age structure will not bring about a secular increase in earnings of a significant magnitude. It is also apparent that the increase in social security contributions will be the central factor generating future price changes in the labor market. 
Figure 11: Index of Gross Wages (2000=100).

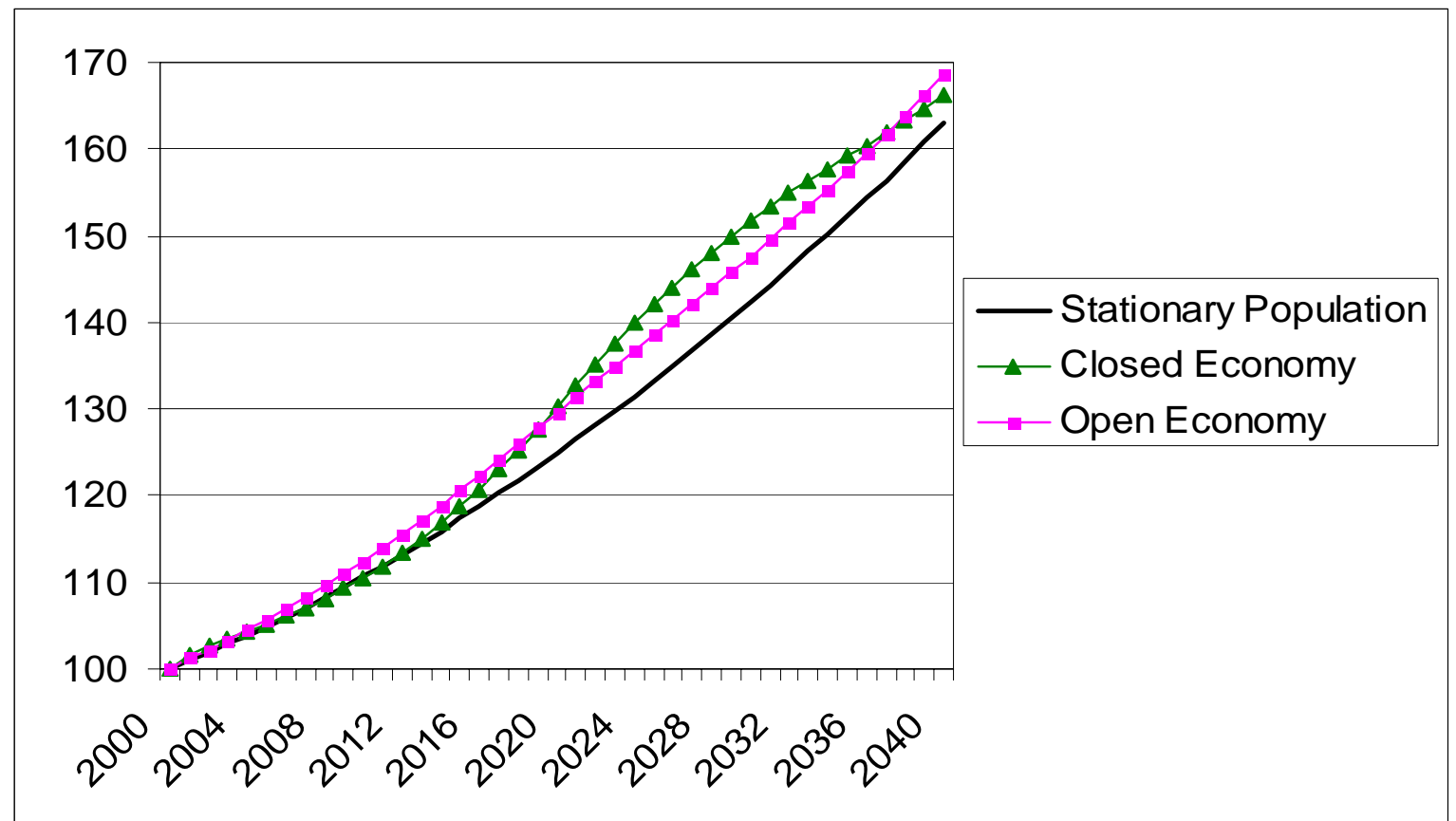

Source: Own calculations, based on Börsch-Supan, Ludwig and Winter (2001). The triangles show the values for a closed aging economy, the squares show those for an open aging economy. As a comparison, the solid line depicts the case of a closed economy with a stationary population. All simulations assume the perpetuation of the present pension system. All figures in real terms and indexed to year $2000=100$.

Figure 12: Index of Net Wages (2000=100).

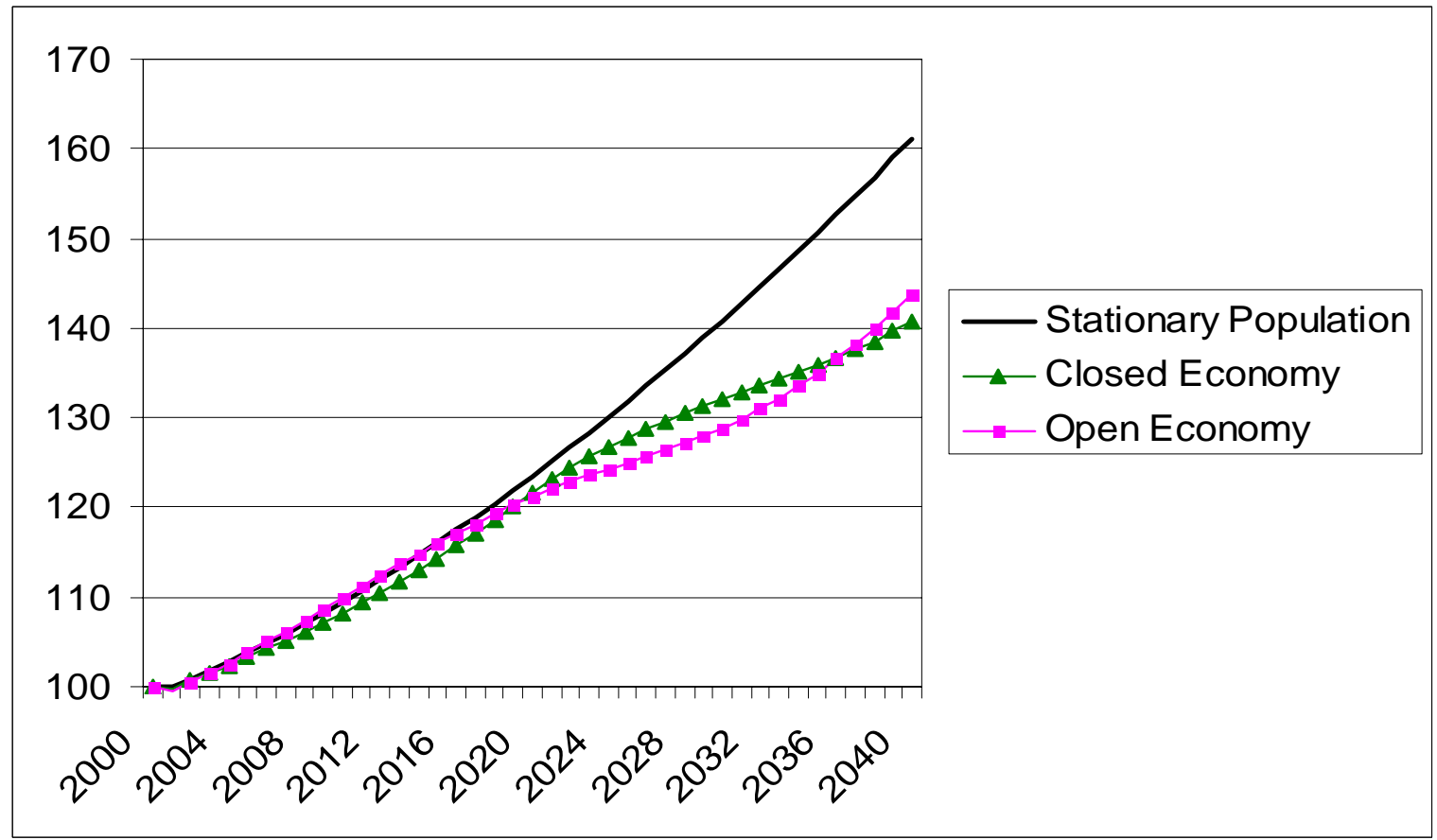

Source: Own calculations, based on Börsch-Supan, Ludwig and Winter (2001). The triangles show the values for a closed aging economy, the squares show those for an open aging economy. As a comparison, the solid line depicts the case of a closed economy with a stationary population. All simulations assume the perpetuation of the present pension system. All figures in real terms and indexed to year $2000=100$. 


\section{Feedback effects of capital intensity}

The shortage of labor accompanying the aging of the population leads to capital substitution. This is shown in figure 13, again drawn from our OLG model. Capital intensity per worker (measured in figures not in units of efficiency) would also increase if the population were to remain constant (or would remain constant per unit of efficiency). The increase accelerates however to the extent that earnings increase relative to interest as we showed in the previous section: ${ }^{2}$

Figure 13: Capital intensity

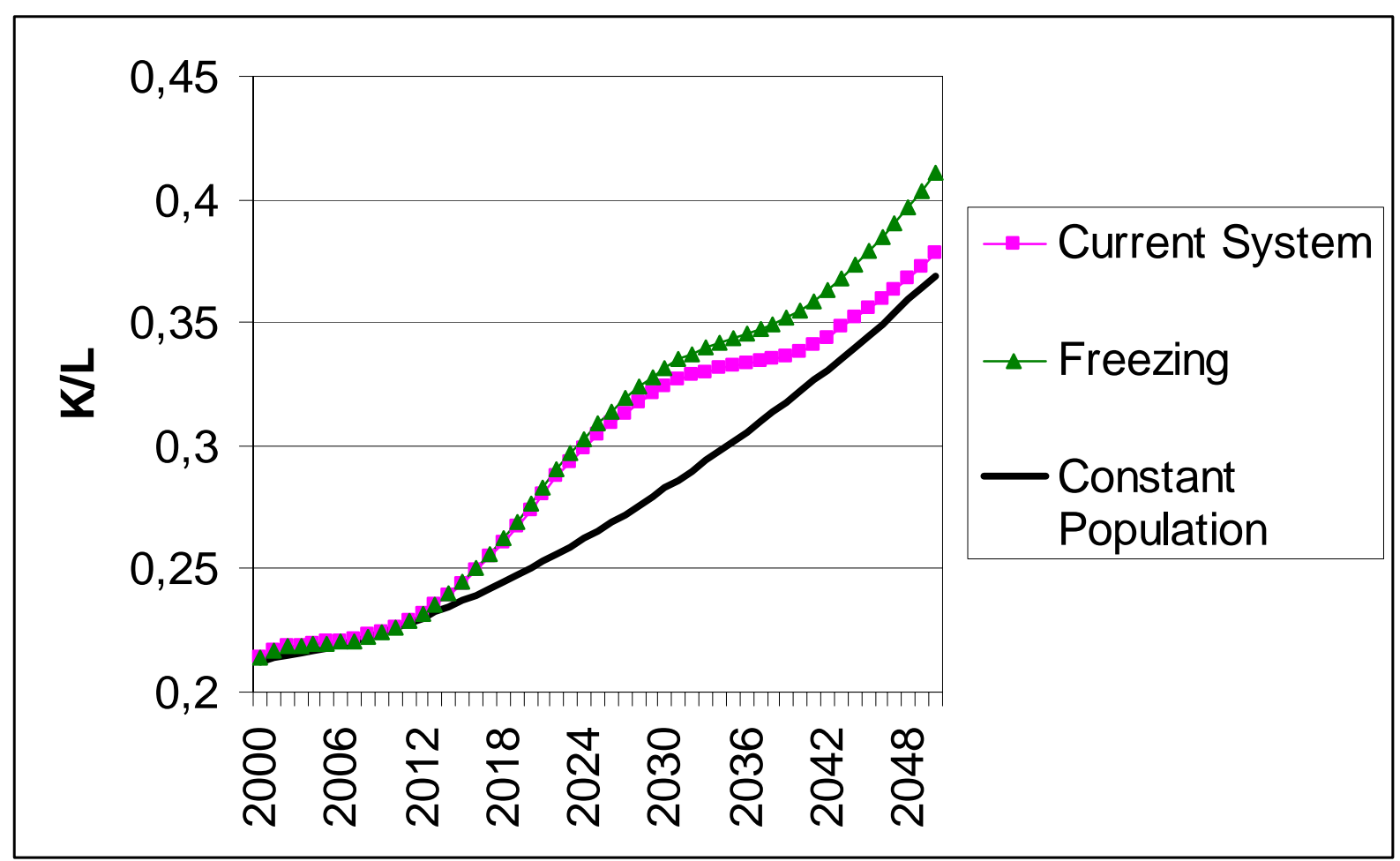

Source: Own calculations, based on Börsch-Supan, Ludwig and Winter (2001). The squares represent the perpetuation of the current pension system, the triangles show the transition to a partly-funded pension system in line with the freezing model. For comparison purposes the case of a constant population (continuous line) is also shown.

We cannot perform this calculation independently of fiscal and social policy. The gradual transition to a multi-pillar model, as initiated by the most recent pension reform, will shift part of retirement income from the pay-as-you-go to the funded system so that the capital stock -

${ }^{2}$ For the development of the interest rate cf. Börsch-Supan, Ludwig and Winter (2001). The interest rate falls during the course of the aging process although this can be largely compensated for by capital mobility within the OECD. 
depending on the crowding out effects - continues to increase. We model this second feedback effect by taking the two extreme cases considered in section 5 into account in figure 13: on the one hand, the perpetuation of the current pay-as-you-go system at current pension levels (and consequently with a passively rising contribution rate, cf. equation 5) and, secondly, the "freezing model”. In the latter case, as the level of pensions falls from cohort to cohort the life-cycle optimization action taken by households results in a slow increase in the savings ratio. The degree of substitution (i.e. the reversal of the "crowding out" effect on private savings exercised by the pay-as-you-go system) is generated implicitly by the elasticity of intertemporal substitution (Table 2) and the other model parameters.

Figure 13 shows that after the year 2030 the difference in pension policy will have a significant influence on capital intensity: while under the present pay-as-you-go system capital intensity will all but return to the same non-aging path after the "shock" to the system caused by the retirement of the baby boom generation, the crowding out effect of pension saving is minimal so that higher capital intensity is maintained over the longer term. ${ }^{3}$

Increasing capital intensity is also accompanied by rising average labor productivity. This is shown in figure 14 as an index in relation to the average labor productivity which would accompany a constant population. The aging-related increase in the amount of capital invested per worker is shown to boost labor productivity by around 6\%. If, in addition, part of retirement income is funded, capital intensity increases even further such that labor productivity now rises to a level about $7 \%$ higher than the level it would have reached if the population had remained constant.

\footnotetext{
${ }^{3}$ It is important to note that there are two forms of crowding out: on the one hand, the crowding out of private pension savings by the pay-as-you-go system and, secondly, the crowding out of other savings by private retirement income.
} 


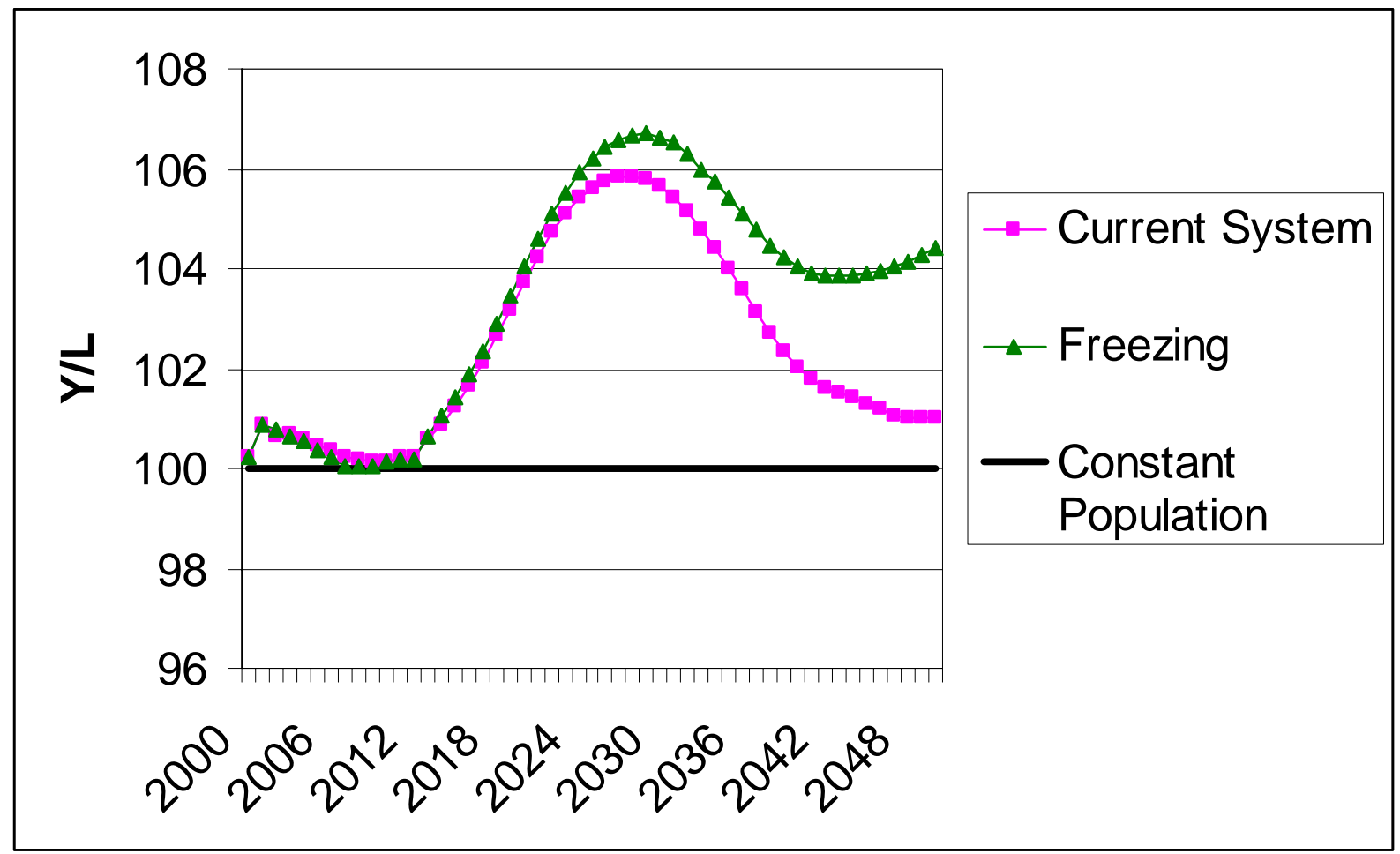

Source: Own calculations, based on Börsch-Supan, Ludwig and Winter (2001). The squares represent the perpetuation of the current pension system, the triangles show the transition to a partly-funded pension system in line with the freezing model. For comparison purposes the case of a constant population (continuous line) is also shown.

The overall results paint a fairly gloomy picture. In section 1 it was argued that, given the smaller relative size of the economically active population, we require an increase in productivity of around 15\% compared with today if we are to be able to produce the same per capita quantity of goods in the year 2035 as we do today (figure 2). Our OLG model shows in figure 14 that at best just about half of this could be achieved by higher capital intensity. Moreover, any possible age-structure related reduction in aggregated labor productivity (cf. figure 10) would reduce the effect of higher capital intensity.

The main message of this section is therefore that without an additional, i.e., "exogenous" increase in productivity of around 0.25 percentage points (from $1.39 \%$ p.a. to $1.65 \%$ p.a.) the per capital level of gross domestic product which would have resulted had the population not aged (i.e. in the case of a constant population) will be almost impossible to maintain. ${ }^{4}$

\footnotetext{
${ }^{4}$ It is important to note the above simulations are based on an exogenous rate of technical progress of $1.39 \%$ per annum which reflects the relevant rate during the calibration period 1960 to 1995 . The absolute per capita level of gross domestic product will not therefore fall.
} 


\section{Structural change and labor mobility}

We conclude our review of the impact of population aging on the labor market with a brief section on structural change elicited by a potential change in consumption behavior. We will illustrate this idea and its possible magnitude without modeling the process in detail.

Consumption behavior changes with increasing age. Figure 15 shows the age-specific shares of nine broad expenditure groups specified in the 1993 income and consumption survey. It is noticeable that spending on goods in the group "transport and communication" falls over the life cycle while goods in the "health and hygiene" group, as well as costs of shelter, account for a growing share of older households’ budgets.

The measurement of age-specific consumption behavior is more complicated than figure 15 suggests, however. As these age-specific expenditure elements are calculated on the basis of cross-sectional data, they confound age, cohort and time effects. They can only be separated using panel data on the structure of spending. This data is unfortunately not available for Germany so that, for the time being, we must make do with the cross-sectional analysis presented in figure 15. Repeated cross-sections show that these age-consumption profiles did not change much over the recent two decades - hence, cohort effects appear to be small and probably do not bias figure 15 to a substantial extent. 
Figure 15: Age-specific distribution of consumer spending across different group of goods

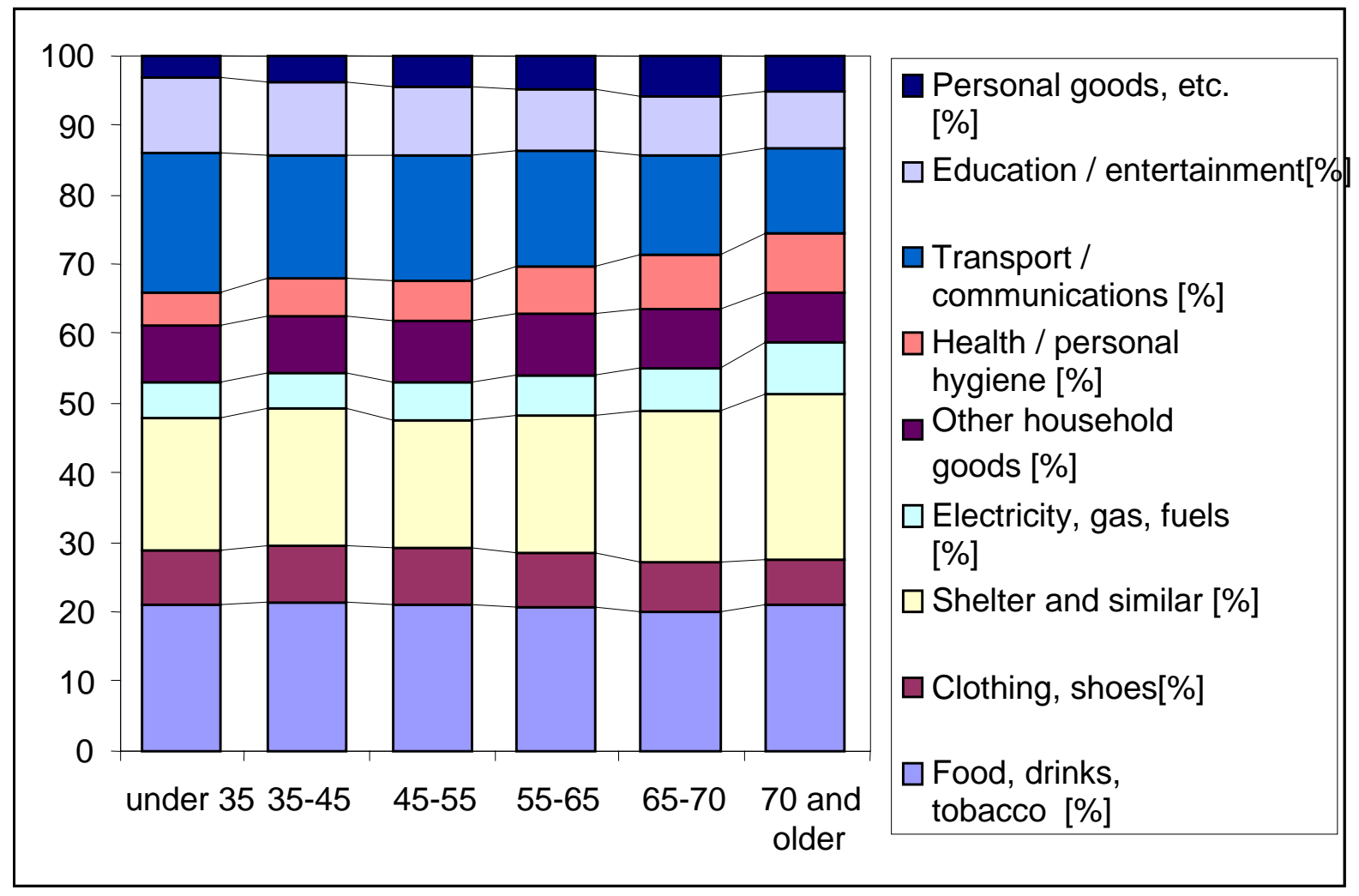

Source: Federal Statistical Office, Survey 15, No. 5, EVS 1993.

Assuming that the pattern of age-specific consumer spending shown in figure 15 remains much the same in the future, we are able to calculate how absolute consumer spending on the nine groups of goods outlined above will develop by multiplying age-specific expenditure with the age-group figures provided by the medium population projection B2 referred to in section 1. Most notably the aggregated expenditure on health calculated on this basis will increase with age while the corresponding spending on transport will decline.

This will impact on employment in these sectors. Figure 16 provides a rough estimate of the quantitative effects. We multiply the expenditure projections with current sector-specific labor productivity (more precisely: with the number of workers per 1 million DM turnover as recorded in the German Annual Statistical Yearbook) to arrive at the time path of workers per sector in the course of population aging. Figure 16 shows the results compared with the year 2000. Employment in the health sector will increase by around 7\%. It will fall in the transport sector by around 5\%. Overall, increases and decreases in employment total 18\% suggesting, on the basis of this rough calculation, that more than a sixth of all workers will need to change their jobs. 
Figure 16: Increase/decrease in employment per goods sector

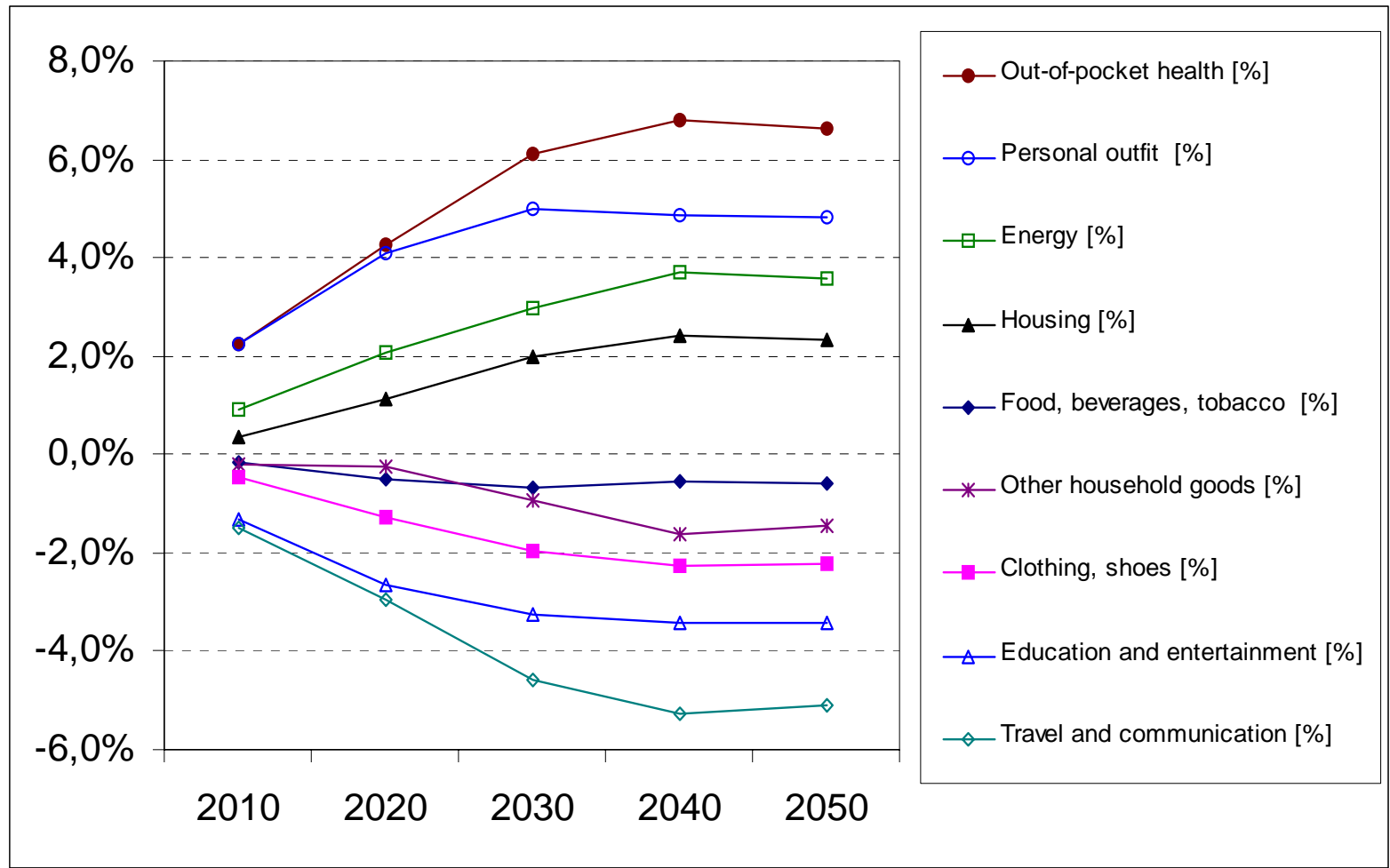

Source: Own calculations based on figure 15, population projection B2, and the annual abstract of statistics "turnover per worker" in each sector.

This is only a rough calculation and merely indicates the most likely broad trend. Neither do the figures account for shifts within each group of goods which may also be subject to opposing age and cohort effects. This is particularly the case for the transport and communications sector, for example, where expenditure in the first subsector, "transport", may in fact be expected to fall with increasing age in contrast with the subsector "communications" where a reduction in spending as shown in figure 15 may well be linked to strong cohort effects.

Nonetheless, we believe that the broad picture presented by figure 16 tends to underestimate rather than overestimate the scale of these changes as shifts within each group of goods in turn trigger changes in employment patterns. Secular developments, such as the development of new products in the health sector which are likely to result in a disproportionate increase in the share of budgets spent on these goods, must also be taken into account. The insight at the core of this section, however, is that structural changes on the goods market will have a powerful impact on sector labor markets. 


\section{Part II: Conclusions for fiscal and social policy}

What are the main results of the descriptive part of this paper? And what priorities should fiscal and social policy consequently follow?

In summary:

- The decline of the support ratio (the number of persons of working age relative to the consuming population) means that, in the year 2035, the labor force will need to be around $15 \%$ more productive in order to attain the level of pro capita production which would have arisen without the impact of aging.

- Only around half of this increase in productivity is likely to be generated "naturally" in the form of higher capital intensity. However, some of this increase might be lost if an older work force shows lower aggregated labor productivity. Hence, a large gap remains.

- An increasing number of jobs will need to be restructured owing to the age-related structural changes in the demand for goods.

- While gross earnings will only respond slightly to population aging, net earnings will drop massively if the statutory pension, health and long-term care insurance schemes continue to be financed largely on a pay-as-you-go basis at today's levels of service.

This summary suggests three high-priority areas for fiscal and social policy:

1. Reducing the contribution and tax burden by reforming social security systems

2. Increasing labor productivity over and above that generated by higher capital intensity by promoting the formation of human capital

3. Promoting, or at the very least not hindering, sectoral labor mobility

As stressed at the beginning of this paper, we do not intend to reiterate the discussion on the reform of social security systems here. This is clearly a herculean task which in Germany has only just been initiated with the amendments currently being made as part of the so-called "Riester pension reform". The literature on this subject is vast and the reader is referred to the relevant surveys.

We wish to cast some light, however, on the feedback effects which played an important role in the discussion in Part I of this paper. The incentive effects of fiscal and social policy on gainful employment have been neglected in many discussions about pension reform. Section 8 addresses the sensitivity of labor force participation of the younger generation with respect to increases in the contribution and tax rates. Section 9 then attempts to quantify the feedback 
effects of pension reform on the labor force participation of the older generation. Section 10 finishes with general policy conclusions.

\section{Feedback effects of fiscal and social policy on the labor force participation of the younger generation}

In the first part of this paper we varied scenarios of gainful employment which we then specified as exogenously given. In section 5 we saw that the high and increasing contribution and tax burden represents the most significant price shock for future labor markets. This section draws together the scanty evidence available to estimate how great the feedback effects on the labor force participation of the younger generation are likely to be as a result of this price shock. Inverting the argument, this also provides an answer to the question as to how fiscal and social policy may contribute to mitigating the impact of aging on the labor market.

One central issue is clearly the extent to which workers see through the "veil" of social security contributions to regard them as insurance premia (Börsch-Supan and Reil-Held, 2001). If workers were to perceive contributions as insurance premia, in other words to regard the social insurance system as a "fair" form of insurance, this would render the wedge between gross and net earnings harmless and there would be no feedback effects on labor supply.

The empirical evidence is primarily based on survey results. In particular the results for younger workers to questions of the type "Do you expect to receive benefits corresponding in value to your social insurance contributions?” reveal that very few of these workers believe there is much equivalence between contributions and benefits and a majority perceive social insurance contributions as a form of tax. A summary of opinion polls of this type performed in Germany and other countries may be found in Börsch-Supan and Miegel (2001). A parallel survey in Germany, France, Italy and Spain also confirmed these results in all four countries (Boeri, Börsch-Supan and Tabellini, 2001). Particularly instructive is the preference expressed by a majority of those surveyed in all four countries to replace 50 percent of their contributions to the pay-as-you-go system (which are clearly perceived as tax) by pension fund and/or insurance contributions of the same amount.

Further empirical conclusions can be drawn from the actual behavior of insured workers, at least to the extent that they are able to "vote with their feet" and opt out of what they regard as an "unfair" form of insurance and to take out alternative cover. This is only possible to a very 
limited degree in the German mandatory pension insurance system. The only way of opting out which is currently available is to leave dependent employment subject to compulsory social insurance contributions altogether. The consequent increase in self-employment and related forms of employment not subject to social security taxation since the mid-eighties is documented in Schnabel (1999). Much less is known about the scale of moonlighting, although reference may be made to the study by Schneider and Ernste (2000) which shows a dramatic increase in the German shadow economy. The cause and scale of these effects are difficult to fathom, as by the very nature of the phenomenon it is difficult to survey.

The most useful evidence stems from that part of the German self-employment sector in Germany in which the workers are entitled to contribute voluntarily to the public retirement scheme. In this sector, around $90 \%$ of all male self-employed paid above-minimum contributions to the public retirement scheme in 1982. This figure had fallen to $16 \%$ by 1997 . The behavior of female self-employed shows a similar development. Schnabel (1999) substantiates the link between this development and the incentive effects of the public retirement scheme using sophisticated econometric techniques.

The “opting-out” rules in the United Kingdom and Hungary also provide empirical examples of revealed preferences. In the UK, over half of the labor force left the state's contributionbased pay-as-you-go system and switched to funded pensions when it was possible to opt freely between either system (Disney, 1996). In Hungary, workers were given the choice of remaining in the state's pay-as-you-go financed system or changing to private, statesubsidized accounts managed either by employees directly or by their employers. Older workers remained in the established system, most of the younger workers left (Palacios and Rocha, 1998).

Overall we conclude that workers do not regard pay-as-you-go social insurance as "fair" insurance premia. The resulting feedback effects are considerable in those sectors where we can observe them. To date, however, data for a broader range of the work force is unavailable. The forthcoming changes in pension and social security law may provide the setting for precisely the type of "policy experiment" that is required to identify these feedback effects.

\section{Feedback effects of fiscal and social policy on the labor force participation of the older generation}

Identifying the feedback effects on the labor force participation of the older generation is somewhat simpler because econometric estimates are available which quantify the influence 
of fiscal and social policy on labor supply. At the core of these estimates are the incentive effects which the pension and tax system exercises on lifetime working patterns.

By 2004 the 1992 pension reform in Germany will have capped but not eliminated the major incentives favoring early retirement. The rules which have applied since 1972 enabled workers to enter early retirement (60 years for women, 63 years for workers with a 35-year contribution record) without incurring any financial penalty at all. Only if the beneficiary's pension is calculated on the basis of the number of years contributions have been paid does the annual pension rise by around $2.5 \%$ if a worker works one year longer. This is however more than cancelled out by the fact that payment of this higher pension is postponed for one year which, given that life expectancy at retirement age is about 17 years, is tantamount to a reduction of about $6 \%$ in the overall period over which pension is received. The cash value of pensions thus falls in line with the deferment of retirement. If this loss is set in relation to the average income a worker could earn in this additional year, in other words if we calculate the implicit tax which the pension system imposes on later retirees, we arrive at very high tax rates. On the basis of the old retirement rules, they exceed 50\%. They will still be around 25\% once the new 1992 pension rules take full effect in the year 2004.

We can draw on four different sources of empirical evidence which demonstrate the strength of the relevant feedback effects on lifetime labor supply. To begin with we can learn from the international variations in the implicit taxation imposed on later retirees. This implicit tax rate fluctuates widely in the 11 countries considered by Gruber and Wise (1999). It is low in Japan and the USA and especially high in Belgium and Italy. The relation between the implicit tax rates and the share of the labor force taking early retirement is shown in logarithmic form in figure 17. The strong correlation is a clear indication of the strength of the incentive effects generated by the implicit taxation of later retirees. 


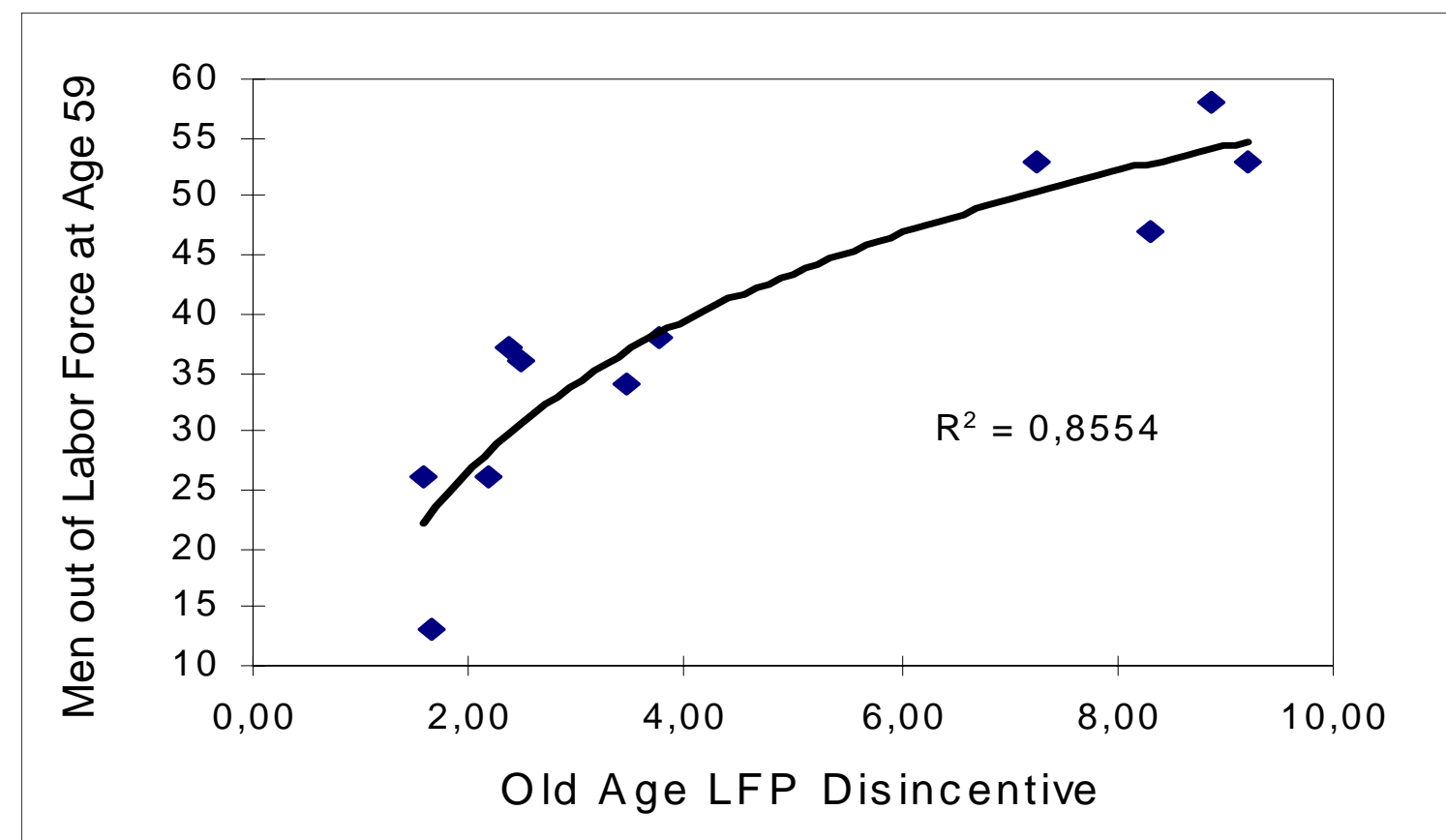

Note: Old age LFP-Disincentive is measured as the implicit rate of tax: the loss in the expected cash value of pension benefits if a worker defers retirement by one year divided by the net earnings received by the worker in this same year. The values have been averaged across all the possible early retirement ages and standardized at a value of between 0 and 10 . The value 0 corresponds, for example, to a zero rate of tax, the value 10 to $100 \%$ for all retirement ages between 60 and 69 years. Source: Börsch-Supan (2000b).

The causal interpretation of a correlation of aggregated cross-sectional data is disputable. To begin with, the causal factor may be the high level of unemployment (which disproportionately affects older workers) rather than the favorable pension treatment for those taking early retirement. Riphahn and Schmidt (1997) however demonstrate that this explanation is not consistent with the onset of higher levels of early retirement - this development was already well under way before mass unemployment became a factor to reckon with. The other argument frequently wielded, namely that early retirement is less the expression of employees' wishes to give up work for leisure than a response on the part of employers attempting to exploit pension law to push through restructuring measures is unconvincing: in fact it shows that the pension law has created incentives for employees and employers alike to profit from early retirement at the cost of the remaining contributors to the pension system.

Econometric studies which, thanks to their quasi-experimental character, provide a more reliable basis for causal interpretations than figure 17 were first presented by Stock and Wise (1990). They used company data in which early retirement incentives have been used to enable specific cohorts to enter early retirement. The predictive validity of these effects for pension plans used in other firms too is demonstrated by Lumbsdaine, Stock and Wise, 
(1992). Their models all show a strong response on the part of workers to the early retirement incentives.

The 1972 pension reform in Germany provided an opportunity of estimating the influence of the low early retirement pension deductions in a "natural experiment”. Börsch-Supan (1992, 2000b) shows that the reduction in pensionable age was not a gradual development but a rapid response to the implementation of the 1972 pension reform. A chronological analysis in particular reveals that the retirement age was skewed towards the earliest possible retirement ages and that, since 1972, there has been a systematic drift in the most typical retirement age even of male workers from 65 years to 60 years. The chronological relationships revealed by figure 18 are amenable to causal interpretation (Börsch-Supan and Schnabel, 1998).

\section{Figure 18: Effect of the 1972 pension reform on the retirement age}

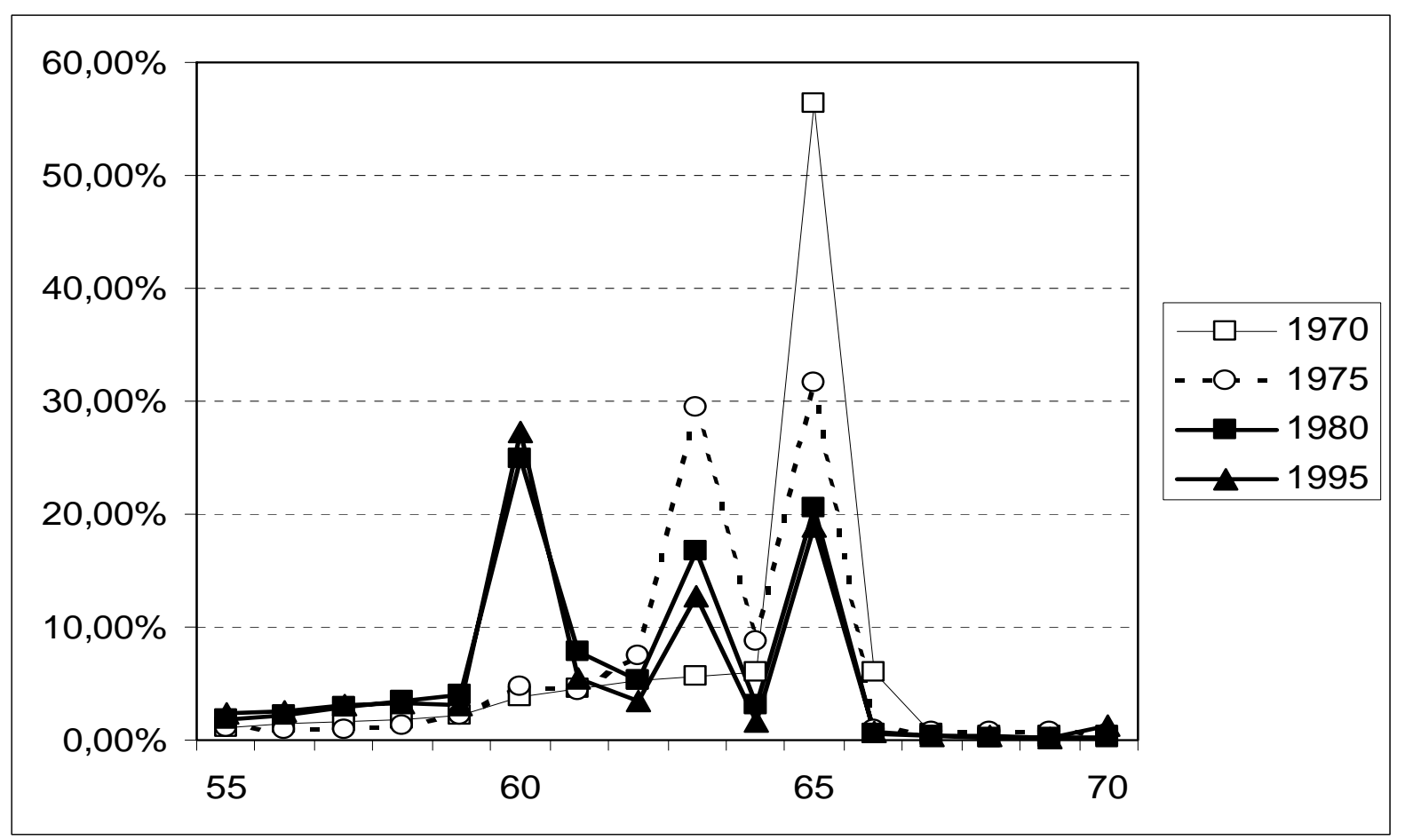

Note: Percentage distribution of age on initial receipt of benefits from the public retirement insurance scheme. Source: Börsch-Supan and Schnabel (1998) based on VDR (1997).

Finally, numerous German econometric studies also confirm that workers clearly respond to the incentive effects inherent in the public retirement scheme (Börsch-Supan, 1992; Schmidt, 1995; Siddiqui, 1997; Börsch-Supan, 2000b). All these studies concur in calculating a robust response to these incentive effects, the magnitude of which implies that the actuarially inadequate deductions for the flexible retirement ages alone have reduced the average pensionable age by at least two years. 


\section{Conclusions: How can fiscal and social policy mitigate the impacts of population aging on the labor market?}

This paper attempted to analyze the most important effects of population aging on the labor market and to illustrate the consequences for fiscal and social policy. What can be done in terms of fiscal and social policy to mitigate the impact of population aging? In order to address this question we draw on the three issues raised at the end of the introduction to second part of this paper.

There is no dissense that the amply discussed age-determined increase in contribution and tax rates will have eminently important effects on future labor markets. While we have little precisely quantifiable evidence, what evidence we do have is qualitatively compelling and suggests that the growing wedge between gross and net earnings will reduce the labor force participation of the younger generation. If the government wants to reduce this wedge, it should strengthen the equivalence principle as much as possible by introducing a "notional defined contribution" (NDC) system for the pay-as-you-go social insurance system. While this change does not change the financial balance of a pay-as-you-go system directly, it changes the incentives in the pension system both for workers and politicians, see BörschSupan (2000c).

The impact of fiscal and social policy on the labor force participation of the older generation is easier to quantify. Simply increasing the retirement-age-specific adjustment factors to about 7 percent per year of earlier retirement would correct the average retirement age upwards by about 2 years. This would also remove the subsidization of early retirees by later retirees which is also difficult for voters to accept - and would, at the same time, reduce the contribution and tax burden of the pay-as-you-go system.

Alongside the reform of social security systems there are, however, two further important areas of policy which, to date, have attracted very little attention in the political discussion about population aging. First, the decrease in the relative size of the economically active population cannot be offset by higher capital intensity. Labor productivity will in fact need to increase over and above this mechanism in order to compensate for the effects of the shift in the age structure on domestic production. The strengthening of human capital formation through education and training thus assumes central importance particularly in the face of population aging.

Second, the change in the structure of consumer goods' and services' demand will trigger additional sectoral mobility. If the government wants to accommodate these structural 
changes, an important task of labor market policy must be to remove current constraints on mobility. Moreover, tax and social policy also have to accommodate increased mobility. For instance, social insurance reforms are likely to put greater weight on occupational pension and possibly even health care schemes. However, the portability of such schemes - a core prerequisite for mobility - runs counter to employers' wish to use company benefit systems as a means of retaining good workers (Lazear, 1995). Hence, an important task of social policy is to create conditions which minimize such curbs on mobility. A second example is taxation of pensions. The deferred taxation of retirement income appears to be the only technically feasible method of ensuring the transparency and portability of occupational pensions, particularly, if they are not of the "defined contribution” type with clearly assigned individual accounts (Börsch-Supan and Lührmann, 2000).

We conclude this paper with some comments on two areas of policy about which we are skeptical. It is advisable for fiscal and social policy to provide incentives for people to have more children or to attract more migrants to Germany? We believe that these two options will not be effective means to address the aging problem. Figure 3 shows that an increase in the birth rate would only begin to be felt after the year 2040 and thus after the peak change in the age structure has already taken place. In addition, as the example of the USA shows, the low birth rate is only one reason for the shift in the age structure of the population, the second is the secular increase in life expectancy. ${ }^{5}$

Immigration is also unlikely to be the promising cushion of the aging process, as it is frequently advertized. While it is theoretically obvious that an influx of young immigrants can compensate for the aging process, in reality two problems arise. First, the domestic labor market would need to be sufficiently flexible to absorb migrant workers and to offer the requisite training. This does not come without costs. In addition, the number of immigrants would have to be sufficiently large. Given the typical age structure of immigrants immigrants to Germany are on average ten years younger than the indigenous population around 750,000 people (workers and family) would need to migrate to Germany every year

\footnotetext{
${ }^{5}$ There are potentially important feedback effects of social policy and fertility. Cigno (1995) examined the interaction between social security and the birth rate using historical times series. The evidence still remains controversial.
} 
up to the year 2035 in order to fully balance out the aging process in Germany. ${ }^{6}$ Such extremely high numbers make such a “solution” unrealistic.

Hence, the main insight for fiscal and social policy is that we have to solve the problems which population aging will impose on the labor markets ourselves: by reforming social insurance, by accumulating more real and human capital and by facilitating structural adjustments.

${ }^{6}$ Börsch-Supan (2000a). Assuming that the unemployment rate among immigrants remains $50 \%$ above the current overall rate for Germany. 


\section{References}

Auerbach, A.J. and L.J. Kotlikoff (1987): Dynamic Fiscal Policy. Cambridge, MA: Cambridge University Press.

Barth et al (1993): “Corporations and the Aging Workforce.” Building the Competitive Workforce: Investing in Human Capital for Corporate Success, ed. Philip H. Mirvis: John Wiley \& Sons.

Birg, H. and A. Börsch-Supan (1999): Für eine neue Aufgabenteilung zwischen gesetzlicher and privater Altersversorgung. Berlin: Gesamtverband der Versicherungswirtschaft.

Boeri, T., A. Börsch-Supan and G. Tabellini (2000), Would you like to shrink or expand the welfare state? The opinions of European Citizens. Mimeo, Bocconi University and the University of Mannheim.

Börsch-Supan, A. (2000a), A Model under Siege: A Case Study of the Germany Retirement Insurance System, The Economic Journal, Vol. 110 No. 461, F24-45.

Börsch-Supan, A. (2000b), Incentive Effects of Social Security on Labor Force Participation: Evidence in Germany and Across Europe, Journal of Public Economics 78, 25-49.

Börsch-Supan, A. (2000c), A Blueprint for Germany's Pension Reform, paper for the workshop "Reforming Old-Age Pension Systems", Herbert-Giersch-Stiftung, Magdeburg, 25-26 May 2000, also available at www.vwl.uni-mannheim.de.

Börsch-Supan, A. and M. Lührmann (2000), Prinzipien der Renten- und Pensionsbesteuerung, Frankfurter Institut: Bad Homburg.

Börsch-Supan, A and Miegel, M (2001): „Pension Reform in Six Countries“: What can we learn from each other?. Springer: Berlin, Heidelberg, New York.

Börsch-Supan, A., A. Ludwig and J. Winter (2001), Aging and International Capital Flows, paper for the Bundesbank conference "The Implications of Aging on Financial Markets and Monetary Policy”, Mai 2001.

Börsch-Supan, A., and A. Reil-Held (2001), How much is Transfer and how much Insurance in a Pay-As-You-Go System? The German Case, Scandinavian Journal of Economics, in press.

Börsch-Supan, A., and R. Schnabel (1998), Social Security and Declining Labor Force Participation in Germany, American Economic Review 88.2, 173-178.

Buchheim, C. (1994), Industrielle Revolutionen, dtv: Munich.

Cigno, A (1995), Public pensions with endogenous fertility, Journal of Public Economics 57, 169-173, 1995.

Diamond, P.A. (1965): National debt in a neoclassical growth model. American Economic Review, 55, 1126-1150.

Disney, R. (1996), Can we Afford to Grow Older?, MIT Press: Cambridge, Mass.

Disney, R. (1999), Notional Account-Based Pension Reform Strategies: An Evaluation, mimeo, University of Nottingham and The World Bank.

Fehr, H. (2000): Pension reform during the demographic transition. Scandinavian Journal of Economics, 102(3), 419-443. 
Gruber, J., and D. Wise (1999), publisher, International Comparison of Social Security Systems, The University of Chicago Press: Chicago.

Hamermesh, D.S. (2001), Older Workers in the Coming Labor "Shortage": Implications of Labor Demand. Paper prepared for the Roundtable on the Demand for Older Workers, The Brookings Institution, March 2001.

Hutchens, R.M. (2001), Employer Surveys, Employer Policies, and Future Demand for Older Workers. Paper prepared for the Roundtable on the Demand for Older Workers, The Brookings Institution, March 2001.

Kotlikoff, L. and D. Wise (1989), Employee Retirement and a Firm's Pension Plan, in D.A. Wise, ed., The Economics of Aging, Chicago: University of Chicago Press, 279-334.

Lazear, E. (1995), Personnel Economics, MIT-Press: Cambridge, Mass.

Lumbsdaine, R.L., J.H. Stock, and D.A. Wise (1992), Three models of Retirement: Computational Complexity versus Predictive Validity, in D.A. Wise, ed., Topics in the Economics of Aging, Chicago: University of Chicago Press, 16-60.

Miles, D. (1999): Modeling the impact of demographic change upon the economy. Economic Journal, 109, 1-36.

Palacios, R. and R. Rocha (1998), The Hungarian Pension System in Transition, Social Protection Discussion Paper Series 9805, The World Bank, Washington, D.C.

Riphahn, R.T., and P. Schmidt (1997), Determinanten des Ruhestandes: Lockt der Ruhestand oder drängt der Arbeitsmarkt? Jahrbücher für Wirtschaftswissenschaften, 48(1), 113147.

Schmidt, P. (1995), Die Wahl des Rentenalters - Theoretische und empirische Analyse des Rentenzugangsverhaltens in West- und Ostdeutschland, Lang: Frankfurt.

Schnabel, R. (1998), Kapitalmarktrenditen und die Rendite der gesetzlichen Rentenversicherung. Working paper, University of Mannheim.

Schnabel, R. (1999), Opting Out of Social Security: Incentives and Participation in the German Public Pension System, SFB504-Discussion Paper No. 99-42, University of Mannheim.

Schneider, F. and D.H. Ernste (2000), Shadow Economies: Size, Causes and Consequences, Journal of Economic Literature 38(1), 77-114.

Siddiqui, S. (1997), The Pension Incentive to Retire: Empirical Evidence for West Germany, Journal of Population Economics 10(4), 463-86.

Stock, J.H., and D.A. Wise (1990), The Pension Inducement to Retire: An Option Value Analysis, in: D.A. Wise (publisher) Issues in the Economics of Aging, Chicago: University of Chicago Press, 1990, 205-30.

United Nations Population Division (2000): World Population Prospects: The 1998 Revision. United Nations, Washington, D.C. 


\begin{tabular}{lll}
\hline \hline Nr. & Author & Title \\
\hline
\end{tabular}

07-19 Jürgen Eichberger

David Kelsey

Burkhard Schipper

07-18 Jürgen Eichberger

Willy Spanjers

07-17 Patrick A. Müller

Jana Janßen

Dominique Jarzina

07-16 Patrick A. Müller

Dagmar Stahlberg

07-15 Axel Börsch-Supan

Anette Reil-Held

Daniel Schunk

07-14 Axel Börsch-Supan

Dirk Krüger

Alexander Ludwig

07-13 Melanie Lührmann

07-12 Axel Börsch-Supan

Anette Reil-Held

Christina Wilke

07-11 Alexander Ludwig

Dirk Krüger

07-10 Daniel Schunk

07-09 Axel Börsch-Supan Anette Reil-Held

Christina Wilke
Ambiguity and Social Interaction

Liquidity and Ambiguity: Banks or Asset Markets?

Applicantsí reactions to selection procedures $\tilde{n}$ Prediction uncertainty as a moderator of the relationship between procedural fairness and organizational attractiveness

The Role of Surprise in Hindsight Bias ñ A Metacognitive Model of Reduced and Reversed Hindsight Bias

Das Sparverhalten deutscher Haushalte: Erste Erfahrungen mit der Riester-Rente

Demographic Change, Relative Factor Prices, International Capital Flows, and their Differential Effects on the Welfare of Generations

Consumer Expenditures and Home Production at Retirement: New Evidence from Germany

Zur Sozialversicherungsfreiheit der

Entgeltumwandlung

On the Consequences of Demographic Change for Rates of Returns to Capital, and the Distribution of Wealth and Welfare

What Determines the Saving Behavior of German Households? An Examination of Saving Motives and Saving Decisions

How an Unfunded Pension System looks like

Defined Benefits but works like Defined

Contributions: The German Pension Reform 